\title{
Synthesis and anticancer activity of dimeric podophyllotoxin derivatives
}

This article was published in the following Dove Press journal:

Drug Design, Development and Therapy

\author{
Cheng-Ting $\mathrm{Zi},{ }^{1-3, *} \mathrm{Liu}$ \\ Yang, ${ }^{2, *}$ Feng-Qing $\mathrm{Xu}{ }^{2}$ \\ Fa-Wu Dong, ${ }^{2}$ Dan Yang, ${ }^{2}$ \\ Yan Li, ${ }^{2}$ Zhong-Tao Ding, ${ }^{3}$ \\ Jun Zhou, ${ }^{2}$ Zi-Hua Jiang, ${ }^{4}$ \\ Jiang-Miao $\mathrm{Hu}^{2}$ \\ 'Key Laboratory of Pu-er Tea Science, \\ Ministry of Education, College \\ of Science, Yunnan Agricultural \\ University, Kunming 65020I, China; \\ ${ }^{2}$ State Key Laboratory of \\ Phytochemistry and Plant Resources \\ in West China, Kunming Institute \\ of Botany, Chinese Academy of \\ Sciences, Kunming 65020I, China; ${ }^{3} \mathrm{Key}$ \\ Laboratory of Medicinal Chemistry \\ for Nature Resource, Ministry of \\ Education, School of Chemical Science \\ and Technology, Yunnan University, \\ Kunming 65009I, China; ${ }^{4}$ Department \\ of Chemistry, Lakehead University, \\ Thunder Bay, ON P7B 5EI, Canada \\ *These authors contributed equally \\ to this work
}

Correspondence: Zi-Hua Jiang

Department of Chemistry, Lakehead University, 955 Oliver Road, Thunder Bay, ON P7B 5EI, Canada

$\mathrm{Tel}+$ I $807766717 \mid$

Fax +l 8073467775

Email zjiang@lakeheadu.ca

Jiang-Miao Hu

State Key Laboratory of Phytochemistry and Plant Resources in West China, Kunming Institute of Botany, Chinese Academy of Sciences, Kunming 65020I, China

Tel $+8687 \mid 65223264$

Fax +86 87। 6522326 I

Email hujiangmiao@mail.kib.ac.cn

\begin{abstract}
Background: Podophyllotoxin is a potent cytotoxic agent and serves as a useful lead compound for the development of antitumor drugs. Several podophyllotoxin-derived antitumor agents, including etoposide, are currently in clinical use; however, their therapeutic efficacy is often limited due to side effects and the development of resistance by cancer cells. Previous studies

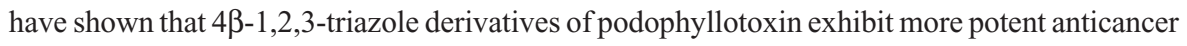
activity and better binding to topoisomerase-II than etoposide. The effect of dimerization of such derivatives on the anticancer activity has not been studied.
\end{abstract}

Methods: Two moieties of podophyllotoxin were linked at the C-4 position via 1,2,3-triazole rings to give a series of novel dimeric podophyllotoxin derivatives. 43-Azido-substituted podophyllotoxin derivatives (23 and $\mathbf{2 4}$ ) were coupled with various dipropargyl functionalized linkers by utilizing the copper-catalyzed azide-alkyne cycloaddition (CuAAC) reaction to provide dimeric products in very good yield. The in vitro anticancer activity of the synthesized compounds was evaluated by MTT assay against a panel of five human cancer cell lines (HL-60, SMMC-7721, A-549, MCF-7, and SW480). The normal BEAS-2B (lung) cell line was also included for study in order to evaluate the cancer selectivity of the most active compound as compared with normal cells.

Results: A group of 16 dimeric podophyllotoxin derivatives with different linkers were synthesized and structurally characterized. Most compounds do not show significant cytotoxicity $\left(\mathrm{IC}_{50}>40 \mathrm{mM}\right)$ against all five cancer cell lines. However, one compound (29) which bears a perbutyrylated glucose residue on the glycerol linker is highly potent against all five cancer cell lines tested, with $\mathrm{IC}_{50}$ values ranging from 0.43 to $3.50 \mu \mathrm{M}$. This compound (29) also shows good selectivity towards cancer cell lines as compared with the normal BEAS-2B (lung) cell line, showing selectivity indexes from 4.4 to 35.7 .

Conclusion: The anticancer activity of dimeric podophyllotoxin derivatives is generally speaking not improved as compared to their monomeric counterparts, and the potency of these dimeric derivatives can be largely affected by the nature of the linker between the two moieties. Among the synthesized derivatives, compound $\mathbf{2 9}$ is significantly more cytotoxic and selective towards cancer cells than etoposide and cisplatin, which are currently in clinical use. Compound $\mathbf{2 9}$ is a promising anticancer drug and needs further studies.

Keywords: podophyllotoxin, dimeric podophyllotoxin derivatives, CuAAC reaction, perbutytylated glucose, antitumor, synthesis

\section{Introduction}

Podophyllotoxin 1 (Figure 1) is the most abundant naturally occurring cyclolignan mainly isolated from podophyllum species and shows strong cytotoxic activity against various cancer cell lines by inhibiting microtubule assembly. ${ }^{1-3}$ Podophyllotoxin is not a clinically useful anticancer drug because of its high toxicity; however, several semisynthetic derivatives, such as etoposide (2) (Figure 1), are clinically used chemotherapeutic agents 


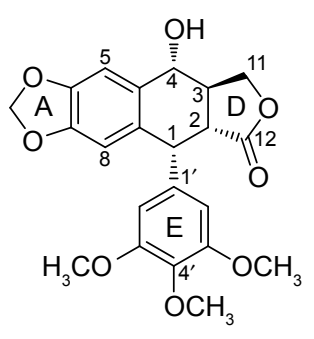

1 Podophyllotoxin

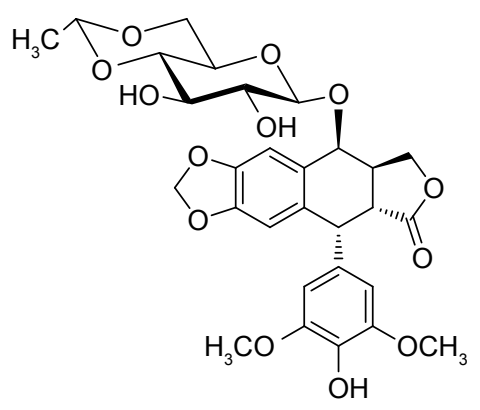

2 Etoposide

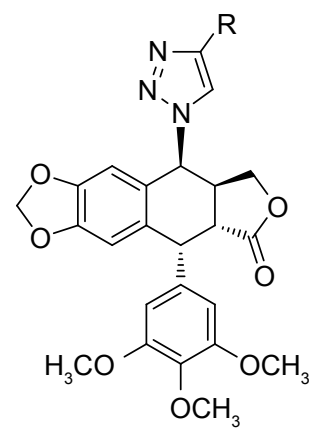

3

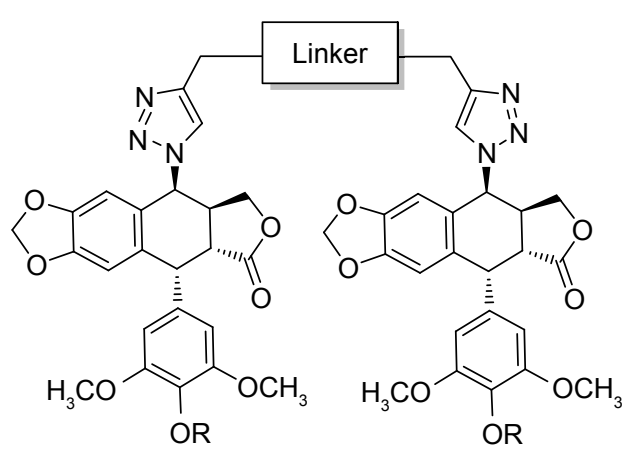

$\mathbf{R}=\mathrm{CH}_{3}, \mathbf{H}$

4

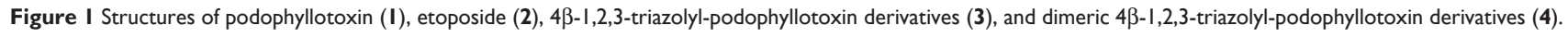

for a number of cancers, including small cell lung cancer, testicular carcinoma, lymphoma, and Kaposi's sarcoma. ${ }^{4-6}$

Earlier reports indicated that the $\beta$-configuration at C-4 of podophyllotoxin scaffold is not favorable for tubulin polymerization inhibition activity. ${ }^{7}$ However, the comparison of the crystal structures of tubulin-DMEP (4'-demethylepipodophyllotoxin) and tubulin-podophyllotoxin suggests that the C-4 $\beta$-configuration does not show any disadvantage for tubulin binding. ${ }^{8}$ For podophyllotoxin derivatives as topoisomerase-II inhibitors, structure-activity relationship (SAR) data show that $4 \beta$-substitution is essential for the anticancer activity. ${ }^{9,10}$

In the attempt to discover less toxic and more effective anticancer agents, many podophyllotoxin derivatives have been synthesized for biological studies. ${ }^{11,12} 4 \beta-1,2,3-$ Triazole derivatives of podophyllotoxin have been shown to exhibit more potent anticancer activity and better binding to topoisomerase-II than etoposide. ${ }^{13-15}$ Recently, we also reported a group of podophyllotoxin glycoconjugates linked via $4 \beta-1,2,3$-triazole functionality as potential antitumor agents. ${ }^{16-18}$ Our studies showed that podophyllotoxin derivatives with a perbutyrylated sugar residue displayed higher activity than their counterparts lacking butyryl groups. ${ }^{16,17}$ There have also been reports on the synthesis of dimeric podophyllotoxin derivatives ${ }^{19,20}$ which exhibited promising in vitro anticancer activity against different human tumour cell lines. In the present study, a group of dimeric podophyllotoxin derivatives 4 (Figure 1), with different linkers have been prepared using the $\mathrm{Cu}(\mathrm{I})$-catalyzed azide-alkyne cycloaddition (CuAAC) reaction. ${ }^{21,22}$ Their synthesis and anticancer activity against five cancer cell lines are described.

\section{Results and discussion Chemical synthesis}

The click reaction of copper(I)-catalyzed Huisgen 1,3-dipolar azide-alkyne cycloaddition (CuAAC) provides 1,4-disubstituted 1,2,3-triazoles, which is a powerful tool for the generation of novel pharmacophores. ${ }^{21,22}$ To access dimeric podophyllotoxin derivatives 4 (Figure 1), di-propargyl functionized linkers are required. Scheme 1 depicts the synthesis of symmetric 1,3-di-O-propargyl glycerol (10) and its glycosylated derivatives (12-14). Initially, we tried direct propargylation of glycerol with propargyl bromide in the presence of sodium hydride $(\mathrm{NaH})$ to prepare $\mathbf{1 0}$. However, the reaction provided complicated products and the strategy was abandoned. Thus, Solketal 5 was treated with propargyl bromide and sodium hydride, and then with $\mathrm{HCl}$ in methanol solution to give diol $\mathbf{6}$ as previously described. ${ }^{23}$ The diol 6 was first converted to bissilyl ether 7 by treatment with tert-butyldimethylsilyl chloride (TBSCl) and imidazole in anhydrous $N, N$-dimethylformamide (DMF). The more labile primary TBS ether in 7 was then 

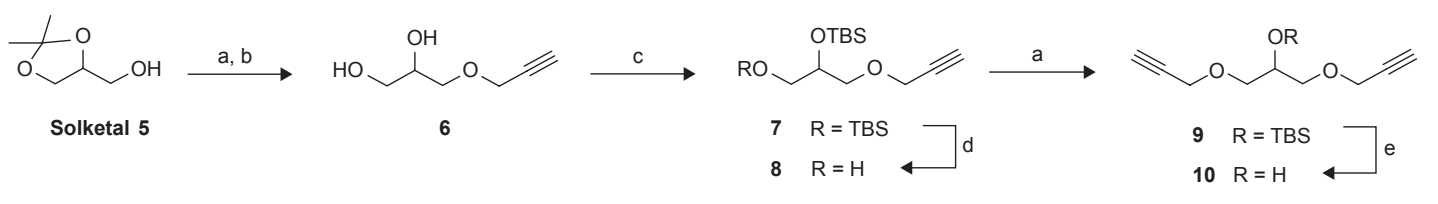

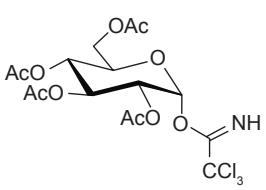

11

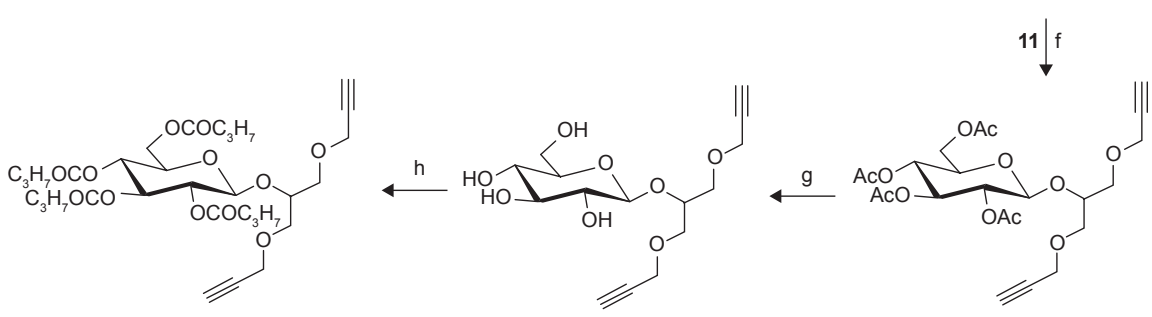

14

12

Scheme I Reagents and reaction conditions: a. NaH, THF, propargyl bromide, reflux, overnight, 56\%; b. $\mathrm{HCl}, \mathrm{CH}_{3} \mathrm{OH}, \mathrm{rt}, 8$ hours, $90 \%$; c. TBSCl, imidazole, DMF, overnight. $80 \%$; d. HF.pyridine, pyridine, THF, rt, 22 hours, 74\%; e. TBAF, $\mathrm{HOAc}, \mathrm{THF}, \mathrm{rt}, 18$ hours, $70 \%$; f. $\mathrm{BF}_{3} \cdot \mathrm{Et}_{2} \mathrm{O}, \mathrm{CH}_{2} \mathrm{Cl}_{2},-78^{\circ} \mathrm{C}, \mathrm{N}_{2}, 63 \%$; g. $\mathrm{CH}_{3} \mathrm{ONa}, \mathrm{CH}_{3} \mathrm{OH}, 12$ hours, $72 \%$; h. $\left(\mathrm{CH}_{3} \mathrm{CH}_{2} \mathrm{CH}_{2} \mathrm{CO}\right)_{2} \mathrm{O}$, pyridine, $0^{\circ} \mathrm{C}-\mathrm{rt}, 12$ hours, $90 \%$.

selectively cleaved with pyridine-HF in pyridine. ${ }^{24}$ Etherification of the primary alcohol $\mathbf{8}$ with propargyl bromide gave nine in $56 \%$ yield. Treatment of 9 with tetrabutylammonium fluoride (TBAF) in tetrahydrofuran (THF) gave alcohol 10. ${ }^{25}$ Next, 10 was allowed to react with the $\alpha$-glucose trichloroacetimidate derivative $11^{26}$ in the presence of $\mathrm{BF}_{3} \cdot \mathrm{Et}_{2} \mathrm{O}$ at $-78^{\circ} \mathrm{C}$ to provide, as expected, only the $\beta$-glycoside 12 in $63 \%$ yield. Then, removal of acetyl groups with $\mathrm{CH}_{3} \mathrm{ONa}$ in $\mathrm{CH}_{3} \mathrm{OH}$ produced 13, which was subjected to perbutyrylation with butyric anhydride in the presence of pyridine to give the perbutyrylated product $\mathbf{1 4}$ in good yield. Interestingly, the anomeric proton of the glucose residue was found significantly downfield and shifted in the ${ }^{1} \mathrm{H}-\mathrm{NMR}$ spectra of the peracetylated derivative $12(\delta 6.45 \mathrm{ppm}, \mathrm{d}, J=8.0 \mathrm{~Hz})$ and perbubyrylated derivative $14(\delta 6.14 \mathrm{ppm}, \mathrm{d}, J=8.0 \mathrm{~Hz})$, while it appears to be normal in non-acylated $13(\delta 4.35 \mathrm{ppm}, \mathrm{d}, J=8.0 \mathrm{~Hz})$. The coupling constant of $8.0 \mathrm{~Hz}$ for the anomeric proton confirms a $\beta$-glycosidic linkage in 12-14.

The synthesis of dipropargyl functionalized linkers based on glucose scaffold is described in Scheme 2. The readily available 6-O-tritylated $\mathbf{1 5}^{27}$ was treated with $\mathrm{TBSCl}$ and imidazole in anhydrous DMF to yield 16 in 80\% yield. Acid catalyzed removal of the trityl group yielded 17 in $93 \%$ yield Compound 17 was then treated with propargyl bromide and $\mathrm{NaH}$ to provide $18(50 \%)$, which was treated with $\mathrm{TBAF}$ in the presence of acetic acid in THF to give triol 19 in $80 \%$ yield. Compound 19 was then subjected to benzylation, acetylation, or butyrylation by treatment with benzyl bromide $/ \mathrm{NaH}$, acetic anhydride/pyridine, or butyric anhydride/pyridine, respectively, to give 20, 21, or $\mathbf{2 2}$ in good to excellent yield.

The azido-substituted podophyllotoxin derivatives needed for the click reaction, $4 \beta$-azido-4-deoxypodophyllotoxin $\mathbf{2 3}$ and $4 \beta$-azido-4-deoxy-4'-demethylpodophyllotoxin 24 , can be readily prepared from podophyllotoxin according to a previous report. ${ }^{28}$ The azides $\mathbf{2 3}$ and $\mathbf{2 4}$ were allowed to react with dipropargyl functionalized linkers 10, 12-14, and 19-22 in the presence of $\mathrm{CuSO}_{4} \cdot 5 \mathrm{H}_{2} \mathrm{O}$, sodium ascorbate in $t$-butyl alcohol and water (1:1) at room temperature to obtain symmetric (25-32) and unsymmetric (33-40) dimeric podophyllotoxin derivatives in very good yield (Scheme 3).

All the products were characterized by ${ }^{1} \mathrm{H}-\mathrm{NMR},{ }^{13} \mathrm{C}$ NMR, ESI-MS, and HRESI-MS data. The presence of the triazole ring in these dimeric podophyllotoxin derivatives

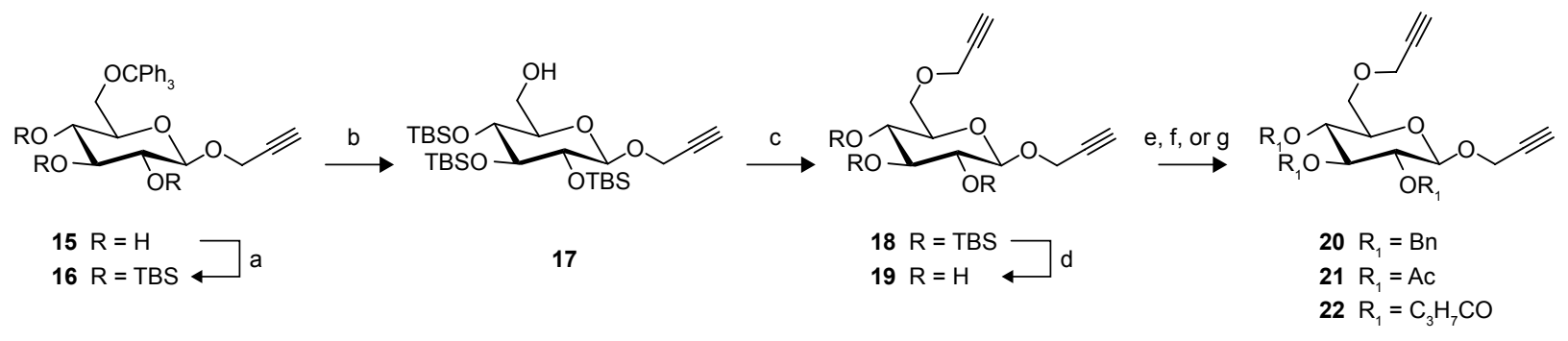

Scheme 2 Reagents and reaction conditions: a. TBSCI, imidazole, DMF, overnight, 80\%; b. formic acid-ether (I:I), 93\%; c. NaH, THF, propargyl bromide, reflux, 50\%; d. TBAF, HOAc, THF, 18 hours, $80 \%$; e. $\mathrm{BnBr}, \mathrm{NaH}, \mathrm{DMF}, 0^{\circ} \mathrm{C}-\mathrm{rt}, 70 \%$; f. Ac $\mathrm{C}_{2} \mathrm{O}$, pyridine, $0^{\circ} \mathrm{C}-\mathrm{rt}, 12$ hours, $91 \%$; g. $\left(\mathrm{CH}_{3} \mathrm{CH}_{2} \mathrm{CH}_{2} \mathrm{CO}_{2} \mathrm{O}, \mathrm{pyridine}, 0^{\circ} \mathrm{C}-\mathrm{rt}, 12 \mathrm{hours}, 93 \%\right.$. 


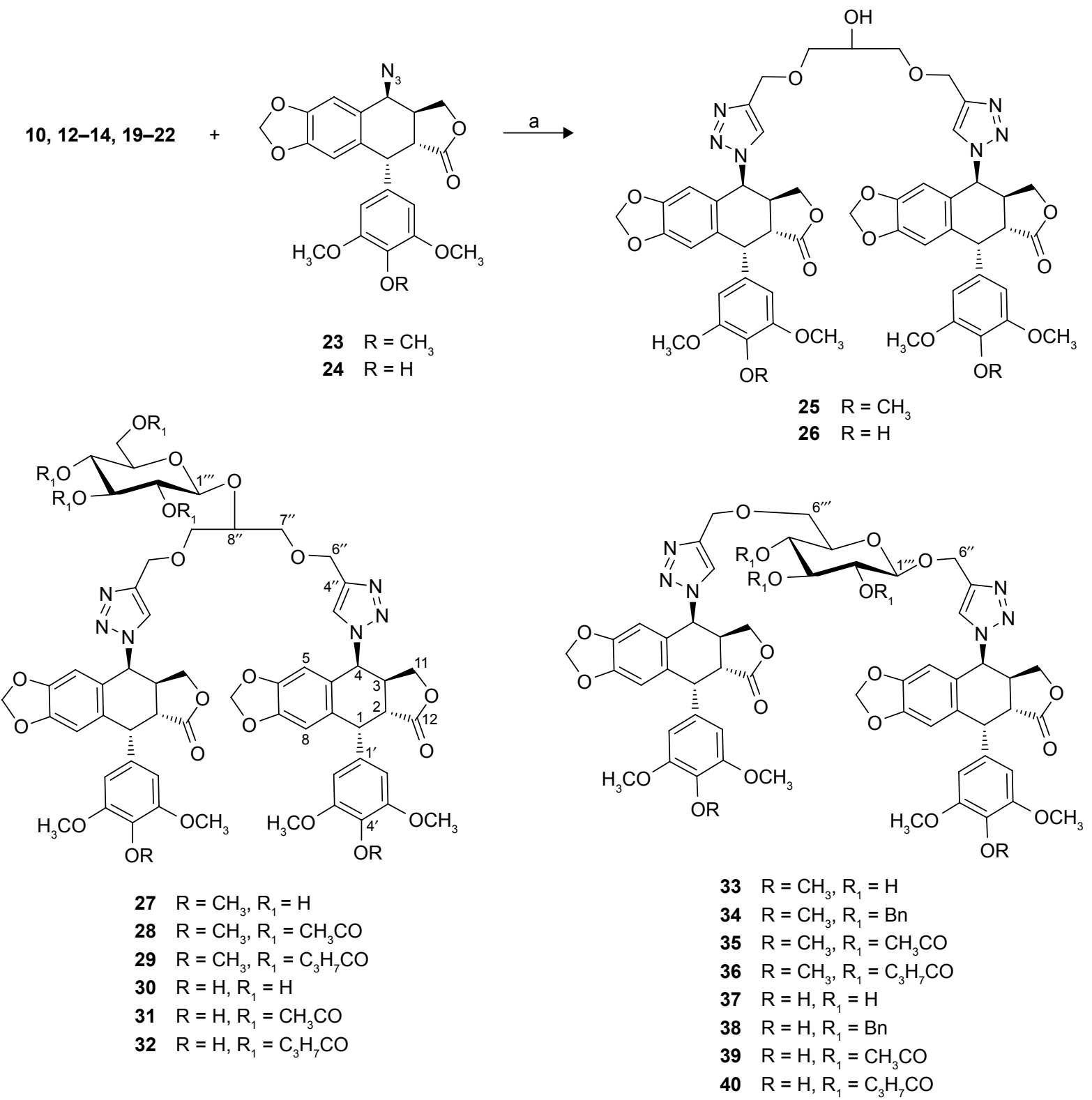

Scheme 3 Reagents and reaction conditions: a. $\mathrm{CuSO}_{4} \cdot 5 \mathrm{H}_{2} \mathrm{O}$, sodium ascorbate, $t-\mathrm{BuOH}: \mathrm{H}_{2} \mathrm{O}(\mathrm{I}: \mathrm{l}), 4$ hours, $\mathrm{rt}$. $74 \%-86 \%$.

was confirmed by the proton signal at around $\delta 7.27-7.96$ $\mathrm{ppm}\left(\mathrm{C}^{5}-\mathrm{H}\right.$ of the triazole ring $)$ in the aromatic region of the ${ }^{1} \mathrm{H}-\mathrm{NMR}$ spectrum, as well as by a pair of carbon signals at around $145 \mathrm{ppm}$ and $124 \mathrm{ppm}$ in the ${ }^{13} \mathrm{C}-\mathrm{NMR}$ spectrum. The proton at $\mathrm{C}-4$ of the podophyllotoxin scaffold of these derivatives appears to be doublet at $5.85-6.22 \mathrm{ppm}$, typically having $J_{3,4}<5.0 \mathrm{~Hz}$ due to a cis relationship between $\mathrm{H}-3$ and H-4. The two podophyllotoxin moieties in symmetric dimeric derivatives (25-32) are identical and give one set of NMR signals. On the other hand, the two podophyllotoxin moieties in unsymmetric dimeric derivatives (33-40) are not identical and produce two sets of NMR signals very close in chemical shifts. ESI-MS and HRESI-MS of all compounds showed the $[\mathrm{M}+\mathrm{Na}]^{+}$or $[\mathrm{M}+\mathrm{H}]^{+}$adduct as the molecular ion.
Proton and carbon-13 NMR spectra for compounds 25-40 are available in the Supplementary Materials.

\section{Anticancer activity}

The in vitro anticancer activity of the synthesized dimeric podophyllotoxin derivatives $\mathbf{2 5 - 4 0}$ was evaluated using the MTT [3-(4,5-dimethylthiazol-2-yl)-2,5-diphenyltetrazolium bromide] assay against five human cancer cell lines, including HL-60 (leukemia), SMMC-7721 (hepatoma), A-549 (lung cancer), MCF-7 (breast cancer), and SW480 (colon cancer). Etoposide (2) and cisplatin were taken as reference compounds and the $\mathrm{IC}_{50}$ (inhibition concentration with 50\% cell growth relative to the control) of all compounds are presented in Table 1. Their $\mathrm{IC}_{50}$ values reveal that most of 
Table I In vitro anticancer activity $\left(\mathrm{IC}_{50}, \mu \mathrm{M}\right)$ of dimeric podophyllotoxin derivatives 25-40 against human tumor cell lines

\begin{tabular}{|c|c|c|c|c|c|c|}
\hline \multirow[t]{2}{*}{ Compounds } & \multicolumn{6}{|c|}{$I C_{50} \pm S D(\mu M)$} \\
\hline & HL-60 & SMMC-772I & A-549 & MCF-7 & SW480 & BEAS-2B \\
\hline 25 & $>40$ & $>40$ & $>40$ & $>40$ & $>40$ & \\
\hline 26 & $>40$ & $>40$ & $>40$ & $>40$ & $>40$ & \\
\hline 27 & $>40$ & $>40$ & $>40$ & $>40$ & $>40$ & \\
\hline 28 & $>40$ & $>40$ & $>40$ & $>40$ & $>40$ & \\
\hline 29 & $0.43 \pm 0.14$ & $1.52 \pm 0.48$ & $0.89 \pm 0.33$ & $\mid .54 \pm 0.4 \mathrm{I}$ & $3.50 \pm 0.45$ & $15.38 \pm 0.14$ \\
\hline 30 & $>40$ & $>40$ & $>40$ & $>40$ & $>40$ & \\
\hline 31 & $>40$ & $>40$ & $>40$ & $>40$ & $>40$ & \\
\hline 32 & $>40$ & $>40$ & $>40$ & $>40$ & $>40$ & \\
\hline 33 & $>40$ & $>40$ & $>40$ & $>40$ & $>40$ & \\
\hline 34 & $20.11 \pm 0.57$ & $>40$ & $>40$ & $>40$ & $>40$ & \\
\hline 35 & $>40$ & $>40$ & $>40$ & $>40$ & $>40$ & \\
\hline 36 & $>40$ & $>40$ & $>40$ & $>40$ & $>40$ & \\
\hline 37 & $>40$ & $>40$ & $>40$ & $>40$ & $>40$ & \\
\hline 38 & $>40$ & $>40$ & $>40$ & $>40$ & $>40$ & \\
\hline 39 & $16.47 \pm 0.44$ & $15.20 \pm 0.56$ & $18.02 \pm 0.47$ & $30.46 \pm 0.99$ & $27.39 \pm 0.78$ & \\
\hline 40 & $14.00 \pm 0.34$ & $15.03 \pm 0.38$ & $19.17 \pm 0.56$ & $29.13 \pm 1.03$ & $29.07 \pm 0.94$ & \\
\hline Etoposide (2) & $0.31 \pm 0.24$ & $8.12 \pm 0.72$ & $11.92 \pm 0.12$ & $32.82 \pm 0.44$ & $17.11 \pm 0.67$ & $11.17 \pm 0.56$ \\
\hline Cisplatin & $1.67 \pm 0.44$ & $6.93 \pm 0.28$ & $7.42 \pm 0.12$ & $|0.85 \pm 0.5|$ & $9.89 \pm 0.53$ & $12.86 \pm 0.25$ \\
\hline
\end{tabular}

these derivatives are not active $\left(\mathrm{IC}_{50}>40 \mu \mathrm{M}\right)$. However, compound 29 is very active against all five cancer cell lines tested, with $\mathrm{IC}_{50}$ values ranging from 0.43 to $3.50 \mu \mathrm{M}$, which is significantly more potent than etoposide and cisplatin. Among the compounds based on a glucose linker (33-40), only 39 and 40 show moderate activity with $\mathrm{IC}_{50}$ values in the range of $14.00-30.45 \mu \mathrm{M}$.

The data in Table 1 indicate that the linking spacer between the two podophyllotoxin moieties can largely affect the activity of these compounds. Compound $\mathbf{2 9}$ which carries a perbutyrylated glucose residue displays much higher potency than those lacking a glucose residue (25), having a free glucose residue (27) or having a peracetylated glucose residue (28). This observation agrees with our earlier reports that several podophyllotoxin glycoconjugates containing perbutyrylated sugar residues show higher anticancer activity than those without butyryl groups. ${ }^{16,17}$ In comparison to $\mathbf{2 9}$, the $4^{\prime}$-demethylated analog $\mathbf{3 2}$ loses its activity, confirming the earlier observation that the substitution group on the $4^{\prime}$-position of podophyllotoxin scaffold can significantly affect the anticancer potency of podophyllotoxin derivatives. ${ }^{29}$ Previously, we reported several groups of monomeric podophyllotoxin derivatives bearing similar structure elements as those dimeric ones in the present study. ${ }^{16,17,29}$ Some of those monomeric derivatives show good anticancer activity with $\mathrm{IC}_{50}$ values in low $\mu \mathrm{M}$ range. Since most of the dimeric podophyllotoxin derivatives in this study display weak anticancer activity, dimerization might not be a good strategy for improving the potency of podophyllotoxin derivatives.

One major drawback of cancer chemotherapy is associated with the low-/non-selective nature of cytotoxic drugs, which attack cancer cells as well as normal cells, leading to serious side effects. To evaluate the degree of selectivity of 29, its growth inhibitory effect on a normal human bronchial epithelial cell line, BEAS-2B, was measured (Table 1). The selectivity index (SI) was expressed as the ratio of the $\mathrm{IC}_{50}$ value of the compound in normal BEAS-2B cell line over that in cancer cell line. ${ }^{30,31}$ A greater SI value indicates that the drug molecule displays higher selectivity towards cancer cells as compared with normal cells. As shown in Table 2, compound 29 has SI values ranging from 4.4 to 35.7 in all five cancer cell lines texted. Literature papers have considered that an SI value greater than $2.0^{32}$ or $3.0^{33}$ is an interesting selectivity index. Importantly, the selectivity indexes of $\mathbf{2 9}$ are much greater than those observed for both clinically used anticancer drugs, etoposide and cisplatin,

Table 2 Selectivity of the cytotoxicity of 29, etoposide (2) and cisplatin to cancer cells as compared with BEAS-2B normal cells

\begin{tabular}{llllll}
\hline Compound & \multicolumn{5}{l}{ Selectivity index $\left(\mathrm{SI}^{\mathrm{a}}\right)$} \\
\cline { 2 - 6 } & HL-60 & SMMC-772I & A-549 & MCF-7 & SW480 \\
\hline $\mathbf{2 9}$ & 35.7 & 10.1 & 17.3 & 10.0 & 4.4 \\
Etoposide (2) & 36.0 & 1.4 & 0.9 & 0.3 & 0.7 \\
Cisplatin & 7.7 & 1.9 & 1.7 & 1.2 & 1.3 \\
\hline
\end{tabular}

Note: aSelectivity index $(\mathrm{SI})=\mathrm{IC}_{50}$ of the compound in BEAS-2B cell line/IC $\mathrm{C}_{50}$ of the compound in cancer cell line. 
except in the case of HL-60 cells where 29 and etoposide have similar SI values. These data suggest that $\mathbf{2 9}$ is significantly more cytotoxic to the cancer cell lines as compared with the normal cell line.

\section{Conclusion}

This paper describes the preparation of a group of dimeric podophyllotoxin derivatives linked via 1,2,3triazole functional groups. $4 \beta$-Azido-podophyllotoxin/4'demethylpodophyllotoxin reacts with various dipropargyl functionalized linkers by copper(I)-catalyzed azide-alkyne cycloaddition (CuAAC) reaction to produce novel dimeric podophyllotoxin derivatives. MTT assay was used to evaluate the in vitro anticancer activity of these compounds against a panel of five human cancer cell lines including HL-60 (leukemia), SMMC-7721 (hepatoma), A-549 (lung cancer), MCF-7 (breast cancer), and SW480 (colon cancer). Most of the synthesized compounds do not show anticancer activity. Notably, compound 29, which bears a perbutyrylated glucose residue on the glycerol linker and is $4^{\prime}-O$-methylated on the E ring, is highly active against all five tested cancer cell lines with $\mathrm{IC}_{50}$ values ranging from 0.43 to $3.50 \mu \mathrm{M}$. As compared with the normal BEAS-2B (lung) cell line, compound 29 is significantly more selective towards all five tested cancer cell lines with selectivity indexes in the range of 4.4-35.7. Taken together, compound $\mathbf{2 9}$ is significantly more cytotoxic and selective towards cancer cells than the clinically used drug etoposide or cisplatin. Further studies are required to study the promising antitumor agent.

\section{Experimental General}

Melting points were uncorrected. Mass spectroscopy (MS) data were obtained in the ESI mode using API Qstar Pulsar instrument. HRMS data were obtained in the ESI mode using LCMS-IT-TOF (Shimadzu, Kyoto, Japan). NMR spectra were acquired using Bruker AV-400 or DRX-500 or Bruker AVANCE III-600 (Bruker BioSpin GmbH, Rheinstetten, Germany) instruments, where tetramethylsilane (TMS) was used as an internal standard. Column chromatography (CC) was performed with flash silica gel (200-300 mesh; Qingdao Makall Group Co., Ltd; Qingdao; China). All reactions were monitored by thin-layer chromatography (TLC) and spots were visualized by spraying $10 \% \mathrm{H}_{2} \mathrm{SO}_{4}$ in ethanol $(\mathrm{EtOH})$ on warm silica gel plates. The human cancer cell lines HL-60, SMMC-7721, A-549, MCF-7, and SW480, and the normal BEAS-2B cell line were purchased from the American Type Culture Collection (ATCC).

\section{I,2-Di-O-tert-butyldimethylsilyl-3-(prop- 2-yn-I-yloxy)propan- I,2-diol (7)}

Imidazole (3.8 g, $55.2 \mathrm{mmol})$ and TBSCl (7.2 g, $47.8 \mathrm{mmol})$ were added to a solution of diol 6 (2.4 g, $18.5 \mathrm{mmol})$ in dimethylformamide (DMF) $(60 \mathrm{~mL})$. The reaction mixture was stirred overnight, and then diluted with $\mathrm{H}_{2} \mathrm{O}(300 \mathrm{~mL})$. The solution was extracted with ether $\left(\mathrm{Et}_{2} \mathrm{O}\right)(3 \times 150 \mathrm{~mL})$ and the combined organic layer was dried over sodium sulfate $\left(\mathrm{Na}_{2} \mathrm{SO}_{4}\right)$. After removing the solvent in vacuo, the residue was purified by $\mathrm{CC}(\mathrm{Rf}=0.20$, petroleum ether: ethyl acetate $=40: 1)$ to give $7(5.2 \mathrm{~g}, 80 \%)$ as a colorless oil. ${ }^{1} \mathrm{H}-\mathrm{NMR}\left(\mathrm{CDCl}_{3}\right.$, $400 \mathrm{MHz}) \delta 4.12\left(\mathrm{~d}, 2 \mathrm{H}, J=2.4 \mathrm{~Hz}, \mathrm{O}-\mathrm{CH}_{2}\right), 3.84-3.78(\mathrm{~m}$, $1 \mathrm{H}), 3.60-3.52$ (m, 3 H), 3.45-3.41 (m, $1 \mathrm{H}), 2.37$ (t, $1 \mathrm{H}$, $J=2.4 \mathrm{~Hz}, \mathrm{C} \equiv \mathrm{CH}), 0.87-0.86(\mathrm{~m}, 18 \mathrm{H}), 0.06-0.03(\mathrm{~m}, 12 \mathrm{H})$; ${ }^{13} \mathrm{C}-\mathrm{NMR}\left(\mathrm{CDCl}_{3}, 100 \mathrm{MHz}\right) \delta 79.7(\mathrm{C} \equiv \mathrm{CH}), 74.2(\mathrm{C} \equiv \mathrm{CH})$, $72.5(\mathrm{O}-\mathrm{CH}), 71.6\left(\mathrm{O}-\mathrm{CH}_{2}\right), 64.8\left(\mathrm{O}-\mathrm{CH}_{2}\right), 58.4\left(\mathrm{CH}_{2}-\mathrm{C} \equiv \mathrm{CH}\right)$, $25.9\left(\mathrm{C}-\mathrm{CH}_{3}\right), 25.8\left(\mathrm{C}-\mathrm{CH}_{3}\right), 25.6\left(\mathrm{C}-\mathrm{CH}_{3}\right), 18.2(\mathrm{Si}-\mathrm{C}), 18.1$ $(\mathrm{Si}-\mathrm{C}),-4.7\left(\mathrm{Si}-\mathrm{CH}_{3}\right),-4.8\left(\mathrm{Si}-\mathrm{CH}_{3}\right),-5.4\left(\mathrm{Si}-\mathrm{CH}_{3}\right),-5.5$ $\left(\mathrm{Si}-\mathrm{CH}_{3}\right)$; ESIMS was calculated for $\mathrm{C}_{18} \mathrm{H}_{38} \mathrm{O}_{3} \mathrm{Si}_{2} \mathrm{Na}[\mathrm{M}+\mathrm{Na}]^{+}$ 381 and was found to be 381 .

\section{2-O-tert-butyldimethylsilyl-3-(prop-2-yn- I-yloxy)propan-I,2-diol (8)}

To a solution of $7(6.8 \mathrm{~g}, 19.0 \mathrm{mmol})$ in dry THF $(60 \mathrm{~mL})$, the HF.pyridine complex $(1.7 \mathrm{~mL})$ and pyridine $(10 \mathrm{~mL})$ were added. The reaction mixture was stirred for 20 hours. After completion of the reaction (TLC monitoring), the solution was diluted with diethyl ether $(100 \mathrm{~mL})$, washed with $0.5 \mathrm{M} \mathrm{HCl}(2 \times 50 \mathrm{~mL})$ and saturated copper sulfate solution $(50 \mathrm{~mL})$, and dried over anhydrous $\mathrm{Na}_{2} \mathrm{SO}_{4}$. After removal of the solvents, the residue was purified by chromatography $(\mathrm{Rf}=0.50$, petroleum ether: ethyl acetate $=4: 1)$ to give $8(3.4 \mathrm{~g}$, $74 \%)$ as a colorless liquid. ${ }^{1} \mathrm{H}-\mathrm{NMR}\left(\mathrm{CDCl}_{3}, 400 \mathrm{MHz}\right) \delta 4.16$ (d, $\left.2 \mathrm{H}, J=2.4 \mathrm{~Hz}, \mathrm{O}-\mathrm{CH}_{2}\right), 3.93-3.88(\mathrm{~m}, 1 \mathrm{H}), 3.67-3.63$ (m, 1 H), 3.60-3.53 (m, 3 H), 2.44 (t, $1 \mathrm{H}, J=2.4 \mathrm{~Hz}), 0.89$ $(\mathrm{s}, 9 \mathrm{H}) 0.10(\mathrm{~s}, 6 \mathrm{H}) ;{ }^{13} \mathrm{C}-\mathrm{NMR}\left(\mathrm{CDCl}_{3}, 100 \mathrm{MHz}\right) \delta 79.7$ $(C \equiv \mathrm{CH}), 74.2(\mathrm{C} \equiv \mathrm{CH}), 72.5(\mathrm{O}-\mathrm{CH}), 71.6\left(\mathrm{O}-\mathrm{CH}_{2}\right), 64.8$ $\left(\mathrm{HO}-\mathrm{CH}_{2}\right), 58.4\left(\mathrm{CH}_{2}-\mathrm{C} \equiv \mathrm{CH}\right), 25.9\left(\mathrm{C}-\mathrm{CH}_{3}\right), 18.2(\mathrm{Si}-\mathrm{C})$, $5.44\left(\mathrm{Si}-\mathrm{CH}_{3}\right)$; ESIMS was calculated for $\mathrm{C}_{12} \mathrm{H}_{24} \mathrm{O}_{3} \mathrm{SiNa}$ $[\mathrm{M}+\mathrm{Na}]^{+} 267$ and found to be 267 .

\section{2-O-tert-butyldimethylsilyl-I,3-di-(prop- 2-yn-I-yloxy)propan- I,2-diol (9)}

Suspension of $\mathrm{NaH}(253.2 \mathrm{mg}, 6.3 \mathrm{mmol})$ in dry THF (5 mL) under $\mathrm{N}_{2}$ was added to a solution of $8(1.0 \mathrm{~g}, 4.2 \mathrm{mmol})$ in dry tetrahydrofuran (THF) $(15 \mathrm{~mL})$ at $0^{\circ} \mathrm{C}$. The mixture was stirred at room temperature for 0.5 hour, and then propargyl bromide $(0.3 \mathrm{~mL}, 4.2 \mathrm{mmol})$ in THF $(15 \mathrm{~mL})$ was quickly 
added and the reaction was refluxed overnight. The reaction mixture was quenched with water, and then THF was removed in vacuo. The residue was extracted with $\mathrm{CH}_{2} \mathrm{Cl}_{2}(2 \times 50 \mathrm{~mL})$, and the organic layer was washed with brine $(100 \mathrm{~mL})$, dried over $\mathrm{Na}_{2} \mathrm{SO}_{4}$, and concentrated under reduced pressure. The residue was purified by $\mathrm{CC}(\mathrm{Rf}=0.40$, petroleum ether: ethyl acetate $=10: 1)$ to obtain $9(1.2 \mathrm{~g}, 56 \%)$. ${ }^{1} \mathrm{H}-\mathrm{NMR}\left(\mathrm{CDCl}_{3}\right.$, $400 \mathrm{MHz}) \delta 4.33-4.32\left(\mathrm{~m}, 2 \mathrm{H}, \mathrm{O}-\mathrm{CH}_{2}\right), 4.19-4.18(\mathrm{~m}, 2 \mathrm{H}$, O-C $\left.\mathrm{H}_{2}\right), 3.79-3.75(\mathrm{~m}, 1 \mathrm{H}), 3.73-3.68(\mathrm{~m}, 3 \mathrm{H}), 3.62-3.58$ (m, $1 \mathrm{H}), 2.43-2.41(\mathrm{~m}, 2 \mathrm{H}, 2 \times \mathrm{C} \equiv \mathrm{CH}), 0.89$ (s, $9 \mathrm{H}), 0.06$ $(\mathrm{s}, 9 \mathrm{H}) ;{ }^{13} \mathrm{C}-\mathrm{NMR}\left(\mathrm{CDCl}_{3}, 100 \mathrm{MHz}\right) \delta 77.7(\mathrm{C} \equiv \mathrm{CH})$, $74.9(\mathrm{C} \equiv \mathrm{CH}), 69.5\left(\mathrm{O}-\mathrm{CH}_{2}\right), 62.4(\mathrm{O}-\mathrm{CH}), 58.7\left(\mathrm{O}-\mathrm{CH}_{2}\right), 25.9$ $\left(\mathrm{C}-\mathrm{CH}_{3}\right), 18.2(\mathrm{Si}-\mathrm{C}), 5.44\left(\mathrm{Si}-\mathrm{CH}_{3}\right)$; ESIMS was calculated for $\mathrm{C}_{15} \mathrm{H}_{26} \mathrm{O}_{3} \mathrm{SiNa}[\mathrm{M}+\mathrm{Na}]^{+} 305$ and was found to be 305 .

\section{I,3-Di-(prop-2-yn-I-yloxy)propan-2-ol ( I 0)}

Acetic acid $(0.3 \mathrm{~mL}, 5.4 \mathrm{mmol})$ and tetra-butylammoniumfluoride trihydrate $(1.5 \mathrm{~mL}, 5.4 \mathrm{mmol})$ were added to a solution of 9 (384.3 $\mathrm{mg}, 1.4 \mathrm{mmol})$ in dry THF $(20 \mathrm{~mL})$ at room temperature. The mixture was stirred for 18 hours, and then the solvent was evaporated under reduced pressure. The crude product was purified by passing through a short column $(\mathrm{Rf}=0.30$, petroleum ether: ethyl acetate $=2: 1)$ to obtain 10 (160 mg, 70\%) as a colorless liquid. ${ }^{1} \mathrm{H}-\mathrm{NMR}$ $\left(\mathrm{CDCl}_{3}, 400 \mathrm{MHz}\right) \delta 4.40-4.28\left(\mathrm{~m}, 2 \mathrm{H}, \mathrm{O}-\mathrm{CH}_{2}\right), 4.18-4.23$ (m, $\left.2 \mathrm{H}, \mathrm{O}-\mathrm{CH}_{2}\right), 3.83-3.76(\mathrm{~m}, 1 \mathrm{H}), 3.70-3.66(\mathrm{~m}, 4 \mathrm{H})$, 2.48-2.45 (m, $2 \mathrm{H}, 2 \times \mathrm{C} \equiv \mathrm{CH}) ;{ }^{13} \mathrm{C}-\mathrm{NMR}\left(\mathrm{CDCl}_{3}, 100 \mathrm{MHz}\right) \delta$ $77.7(\mathrm{C} \equiv \mathrm{CH}), 74.7(\mathrm{C} \equiv \mathrm{CH}), 69.5\left(\mathrm{O}-\mathrm{CH}_{2}\right), 62.4(\mathrm{O}-\mathrm{CH}), 58.7$ $\left(\mathrm{O}-\mathrm{CH}_{2}\right)$; ESIMS was calculated for $\mathrm{C}_{9} \mathrm{H}_{12} \mathrm{O}_{3} \mathrm{Na}[\mathrm{M}+\mathrm{Na}]^{+} 191$ and was found to be 191 . The ${ }^{1} \mathrm{H}-\mathrm{NMR}$ and ${ }^{13} \mathrm{C}$-NMR data are in full agreement with those reported in the literature. ${ }^{25}$

\section{I,3-Di-(prop-2-yn- I-yloxy)prop-2-y| 2,3,4,6-tetra-O-acetyl- $\beta$-D- glucopyranoside ( I 2)}

A solution of $\mathrm{BF}_{3} \cdot \mathrm{Et}_{2} \mathrm{O}(87.2 \mu \mathrm{L}, 0.7 \mathrm{mmol})$ in dichloromethane $(1 \mathrm{~mL})$ at $-78^{\circ} \mathrm{C}$ was added dropwise to a solution of $\mathbf{1 1}^{26}$ (225 mg, $\left.0.5 \mathrm{mmol}\right)$ and $\mathbf{1 0}(77 \mathrm{mg}, 0.5 \mathrm{mmol})$ in dry $\mathrm{CH}_{2} \mathrm{Cl}_{2}(2 \mathrm{~mL})$. The reaction mixture was brought to room temperature and stirred for 1 hour, and then $\mathrm{Et}_{3} \mathrm{~N}(0.1 \mathrm{~mL})$ was added to the mixture, followed by addition of $\mathrm{AcOH}$ $(0.1 \mathrm{~mL})$. The solvent was evaporated and the residue was purified by $\mathrm{CC}(\mathrm{Rf}=0.60$, petroleum ether: ethyl acetate $=1: 1)$ to obtain 12 (143.7 mg, 63\%). ${ }^{1} \mathrm{H}-\mathrm{NMR}\left(\mathrm{CDCl}_{3}, 400 \mathrm{MHz}\right)$ $\delta 6.45$ (d, $\left.1 \mathrm{H}, J=8.0 \mathrm{~Hz}, \mathrm{C}^{1}-\mathrm{H}\right), 5.20$ (t, $\left.1 \mathrm{H}, J=10.0 \mathrm{~Hz}\right)$, 5.08 (t, $1 \mathrm{H}, J=10.0 \mathrm{~Hz}), 5.03-4.97(\mathrm{~m}, 1 \mathrm{H}), 4.57-4.55$ (m, $1 \mathrm{H}), 4.29-4.28$ (m, $2 \mathrm{H}), 4.25-4.24$ (m, $1 \mathrm{H}), 4.18-4.15$ (m, $2 \mathrm{H}), 3.99-3.95$ (m, $1 \mathrm{H}), 3.89-3.86$ (m, $1 \mathrm{H}), 3.72-3.60$ (m, $5 \mathrm{H}), 2.45-2.43(\mathrm{~m}, 2 \mathrm{H}, 2 \times \mathrm{C} \equiv \mathrm{CH}), 2.09-2.00(\mathrm{~m}, 12 \mathrm{H}$, $\left.4 \times \mathrm{COCH}_{3}\right) ;{ }^{13} \mathrm{C}-\mathrm{NMR}\left(\mathrm{CDCl}_{3}, 100 \mathrm{MHz}\right) \delta 170.7(\mathrm{C}=\mathrm{O})$, $170.3(\mathrm{C}=\mathrm{O}), 170.2(\mathrm{C}=\mathrm{O}), 169.4(\mathrm{C}=\mathrm{O}), 101.0(\mathrm{C}-1), 76.2$ $(\mathrm{C} \equiv \mathrm{CH}), 74.8(\mathrm{O}-\mathrm{CH}), 74.4(\mathrm{C} \equiv \mathrm{CH}), 72.7,71.8,71.2,69.2$, $68.3\left(\mathrm{O}-\mathrm{CH}_{2}\right), 61.8(\mathrm{C}-6), 58.6\left(\mathrm{O}-\mathrm{CH}_{2}\right), 20.7\left(\mathrm{COCH}_{3}\right)$, $20.7\left(\mathrm{COCH}_{3}\right), 20.6\left(\mathrm{COCH}_{3}\right), 20.5\left(\mathrm{COCH}_{3}\right)$; ESIMS was calculated for $\mathrm{C}_{23} \mathrm{H}_{30} \mathrm{O}_{12} \mathrm{Na}[\mathrm{M}+\mathrm{Na}]^{+} 521$ and was found to be 521 .

\section{I,3-Di-(prop-2-yn- I-yloxy)prop-2-yl $\beta$-D- glucopyranoside (13)}

To a solution of 12 (115 mg, $0.2 \mathrm{mmol})$ in $\mathrm{CH}_{3} \mathrm{OH}(2 \mathrm{~mL})$ sodium methoxide $(4.2 \mathrm{mg}, 0.07 \mathrm{mmol}$ ) was added. The resulting mixture was stirred for 24 hours (reaction monitored by TLC) and then the $\mathrm{pH}$ of the medium was adjusted to 7.0 by addition of $\mathrm{HCl}$ solution $\left(1 \mathrm{M}, \mathrm{H}_{2} \mathrm{O}\right)$. The solvent was concentrated and the residue was purified by $\mathrm{CC}$ ( $\left.\mathrm{Rf}=0.20, \mathrm{CHCl}_{3}: \mathrm{CH}_{3} \mathrm{OH}=9: 1\right)$ to obtain the desired product 13 (54.9 mg, 72\%). ${ }^{1} \mathrm{H}-\mathrm{NMR}\left(\mathrm{CD}_{3} \mathrm{OD}, 400 \mathrm{MHz}\right) \delta 4.35$ (d, $\left.1 \mathrm{H}, J=8.0 \mathrm{~Hz}, \mathrm{C}^{1}-\mathrm{H}\right), 4.30-4.27(\mathrm{~m}, 1 \mathrm{H}), 4.19$ (t, $4 \mathrm{H}$, $\left.J=2.4 \mathrm{~Hz}, 2 \times \mathrm{O}_{-} \mathrm{CH}_{2}\right), 4.00-3.86(\mathrm{~m}, 3 \mathrm{H}), 3.72-3.64(\mathrm{~m}$, $4 \mathrm{H}), 3.35-3.27$ (m, $2 \mathrm{H}), 3.20-3.16$ (m, $1 \mathrm{H}), 2.87-2.85$ (m, $2 \mathrm{H}, 2 \times \mathrm{C} \equiv \mathrm{CH}) ;{ }^{13} \mathrm{C}-\mathrm{NMR}\left(\mathrm{CD}_{3} \mathrm{OD}, 100 \mathrm{MHz}\right) \delta 104.7(\mathrm{C}-1)$, $81.0(\mathrm{C} \equiv \mathrm{CH}), 77.8(\mathrm{C} \equiv \mathrm{CH}), 76.1,75.9,75.1,75.0,71.5$ $\left(\mathrm{O}-\mathrm{CH}_{2}\right), 62.7(\mathrm{C}-6), 59.3\left(\mathrm{O}-\mathrm{CH}_{2}\right)$; ESIMS was calculated for $\mathrm{C}_{15} \mathrm{H}_{22} \mathrm{O}_{8} \mathrm{Na}[\mathrm{M}+\mathrm{Na}]^{+} 353$ and was found to be 353 .

\section{I,3-Di-(prop-2-yn- I-yloxy)prop- 2-yl 2,3,4,6-tetra-O-butyryl- $\beta$-D- glucopyranoside (14)}

Butyric anhydride $(0.3 \mathrm{~mL}, 2 \mathrm{mmol})$ was added to a solution of $13(66.0 \mathrm{mg}, 0.2 \mathrm{mmol})$ in pyridine $(2 \mathrm{~mL})$ at $0^{\circ} \mathrm{C}$. The reaction mixture was stirred for 12 hours and then was diluted with water $(5 \mathrm{~mL})$ and extracted with ethyl acetate $(3 \times 5 \mathrm{~mL})$. The organic layer was washed with $10 \%$ aqueous hydrochloric acid $(10 \mathrm{~mL})$ and brine $(10 \mathrm{~mL})$. The organic layer was dried over magnesium sulfate and evaporated to give a residue, which was purified by $\mathrm{CC}(\mathrm{Rf}=0.20$, petroleum ether: ethyl acetate=9:1) to obtain $14(109.8 \mathrm{mg}, 90 \%)$. ${ }^{1} \mathrm{H}-\mathrm{NMR}\left(\mathrm{CDCl}_{3}, 400 \mathrm{MHz}\right) \delta 6.14\left(\mathrm{~d}, 1 \mathrm{H}, J=8.0 \mathrm{~Hz}, \mathrm{C}^{1}-\mathrm{H}\right)$, $5.23(\mathrm{t}, 1 \mathrm{H}, J=9.2 \mathrm{~Hz}), 5.10(\mathrm{t}, 1 \mathrm{H}, J=9.2 \mathrm{~Hz}), 5.05-4.99$ $(\mathrm{m}, 1 \mathrm{H}), 4.58-4.55(\mathrm{~m}, 1 \mathrm{H}), 4.28(\mathrm{~d}, 2 \mathrm{H}, J=2.4 \mathrm{~Hz}$, O-CH $\mathrm{CH}_{2}, 4.21-4.19$ (m, $\left.1 \mathrm{H}\right), 4.16\left(\mathrm{~d}, 2 \mathrm{H}, \mathrm{J}=2.4 \mathrm{~Hz}, \mathrm{O}-\mathrm{CH}_{2}\right)$, 3.98-3.85 (m, 2 H), 3.72-3.70 (m, 4 H), 3.63-3.60 (m, 2 H, $2 \times \mathrm{C} \equiv \mathrm{CH}), 2.44-2.41\left(\mathrm{~m}, 2 \mathrm{H}, \mathrm{COCH}_{2}\right), 2.33-2.20(\mathrm{~m}, 6 \mathrm{H}$, $\left.3 \times \mathrm{COCH}_{2}\right), 1.66-1.54\left(\mathrm{~m}, 8 \mathrm{H}, 4 \times \mathrm{CH}_{2} \mathrm{CH}_{3}\right), 0.95-0.88(\mathrm{~m}$, $\left.12 \mathrm{H}, 4 \times \mathrm{CH}_{2} \mathrm{CH}_{3}\right) ;{ }^{13} \mathrm{C}-\mathrm{NMR}\left(\mathrm{CDCl}_{3}, 100 \mathrm{MHz}\right) \delta 173.3$ 
$(\mathrm{C}=\mathrm{O}), 172.7(\mathrm{C}=\mathrm{O}), 172.0(\mathrm{C}=\mathrm{O}), 171.9(\mathrm{C}=\mathrm{O}), 101.0$ (C-1), $76.0(\mathrm{C} \equiv \mathrm{CH}), 74.8(\mathrm{O}-\mathrm{CH}), 74.4(\mathrm{C} \equiv C \mathrm{H}), 71.9,70.9$, 70.1, 69.3, $68.0\left(\mathrm{O}-\mathrm{CH}_{2}\right), 68.0\left(\mathrm{O}-\mathrm{CH}_{2}\right), 61.7(\mathrm{C}-6), 58.6$ $\left(\mathrm{O}-\mathrm{CH}_{2}\right), 35.9\left(\mathrm{COCH}_{2}\right), 35.8\left(\mathrm{COCH}_{2}\right), 35.8\left(\mathrm{COCH}_{2}\right)$, $35.8\left(\mathrm{COCH}_{2}\right), 18.2\left(\mathrm{CH}_{2} \mathrm{CH}_{3}\right), 18.2\left(\mathrm{CH}_{2} \mathrm{CH}_{3}\right), 18.2$ $\left(\mathrm{CH}_{2} \mathrm{CH}_{3}\right), 18.2\left(\mathrm{CH}_{2} \mathrm{CH}_{3}\right), 13.6\left(\mathrm{CH}_{2} \mathrm{CH}_{3}\right), 13.5\left(\mathrm{CH}_{2} \mathrm{CH}_{3}\right)$, $13.5\left(\mathrm{CH}_{2} \mathrm{CH}_{3}\right), 13.5\left(\mathrm{CH}_{2} \mathrm{CH}_{3}\right)$; ESIMS was calculated for $\mathrm{C}_{31} \mathrm{H}_{46} \mathrm{O}_{12} \mathrm{Na}[\mathrm{M}+\mathrm{Na}]^{+} 633$ and was found to be 633 .

\section{Prop-2-yn-I-yl 2,3,4-tri-O-tert- butyldimethylsilyl-6-O-trityl- $\beta-D$ - glucopyranoside (16)}

Imidazole (2.5 g, $36.0 \mathrm{mmol})$ and TBSCl $(4.9 \mathrm{~g}, 32.5 \mathrm{mmol})$ were added to a solution of $\mathbf{1 5}^{27}$ (4.2 g, $9.0 \mathrm{mmol}$ ) in DMF $(50 \mathrm{~mL})$. The reaction mixture was stirred overnight, and then diluted with $\mathrm{H}_{2} \mathrm{O}(200 \mathrm{~mL})$. The solution was extracted with $\mathrm{CH}_{2} \mathrm{Cl}_{2}$, and the organic layer dried over $\mathrm{Na}_{2} \mathrm{SO}_{4}$. After removing the solvent in vacuo, the residue was purified by $\mathrm{CC}(\mathrm{Rf}=0.30$, petroleum ether: ethyl acetate $=30: 1)$ to give $\mathbf{1 6}(5.9 \mathrm{~g}, 80 \%)$ as a colorless oil. ${ }^{1} \mathrm{H}-\mathrm{NMR}\left(\mathrm{CDCl}_{3}, 400 \mathrm{MHz}\right)$ d7.52-7.24 (m, $15 \mathrm{H}, \mathrm{Ar}-\mathrm{H}), 4.57$ (d, $\left.1 \mathrm{H}, J=6.8 \mathrm{~Hz}, \mathrm{C}^{1}-\mathrm{H}\right)$, 4.54 (d, $\left.2 \mathrm{H}, J=2.4 \mathrm{~Hz}, \mathrm{O}-\mathrm{CH}_{2}\right), 3.56-3.52(\mathrm{~m}, 1 \mathrm{H}), 3.45-$ 3.38 (m, 4 H), 3.25-3.21 (m, $1 \mathrm{H}), 2.49$ (t, $1 \mathrm{H}, J=2.4 \mathrm{~Hz}$, $\mathrm{C} \equiv \mathrm{CH}), 0.95-0.65(\mathrm{~s}, 27 \mathrm{H}), 0.20-0.05(\mathrm{~s}, 18 \mathrm{H}) ;{ }^{13} \mathrm{C}-\mathrm{NMR}$ $\left(\mathrm{CDCl}_{3}, 100 \mathrm{MHz}\right) \delta 144.1,128.8,127.8,126.9,100.3$ (C-1), 86.3, $78.7(\mathrm{C} \equiv \mathrm{CH}), 78.7(\mathrm{C} \equiv C \mathrm{H}), 76.2,75.3,74.9$, 71.5, 63.8 (C-6), $55.3\left(\mathrm{O}-\mathrm{CH}_{2}\right), 26.0(\mathrm{Si}-\mathrm{C}), 25.9(\mathrm{Si}-\mathrm{C})$, $25.8(\mathrm{Si}-\mathrm{C}), 18.3\left(\mathrm{C}-\mathrm{CH}_{3}\right), 18.2\left(\mathrm{C}-\mathrm{CH}_{3}\right), 17.9\left(\mathrm{C}-\mathrm{CH}_{3}\right),-3.8$ $\left(\mathrm{Si}-\mathrm{CH}_{3}\right),-3.9\left(\mathrm{Si}-\mathrm{CH}_{3}\right),-4.0\left(\mathrm{Si}-\mathrm{CH}_{3}\right),-4.7\left(\mathrm{Si}_{-} \mathrm{CH}_{3}\right),-4.7$ $\left(\mathrm{Si}-\mathrm{CH}_{3}\right),-5.2\left(\mathrm{Si}-\mathrm{CH}_{3}\right)$; ESIMS was calculated for $\mathrm{C}_{46} \mathrm{H}_{70} \mathrm{O}_{6}$ $\mathrm{Si}_{3} \mathrm{Na}[\mathrm{M}+\mathrm{Na}]^{+} 825$ and was found to be 825 .

\section{Prop-2-yn-I-yl 2,3,4-tri-O-tert-} butyldimethylsilyl- $\beta$-D-glucopyranoside (I 7) A solution of formic acid in ether $(30 \mathrm{~mL}: 30 \mathrm{~mL})$ was added dropwise to a solution of $\mathbf{1 6}(1.2 \mathrm{~g}, 1.5 \mathrm{mmol})$ in diethyl ether $(30 \mathrm{~mL})$ at room temperature. The mixture was stirred for 3 hours, then diluted with water $(30 \mathrm{~mL})$, and quenched via careful addition of solid potassium carbonate $\left(\mathrm{K}_{2} \mathrm{CO}_{3}\right)$. The layers were separated, and the aqueous layer was extracted with $\mathrm{Et}_{2} \mathrm{O}(3 \times 30 \mathrm{~mL})$, and the resulting organic layers were combined and concentrated in vacuo. The residue was dissolved in $\mathrm{CH}_{3} \mathrm{OH}(40 \mathrm{~mL})$, treated with $\mathrm{K}_{2} \mathrm{CO}_{3}$ $(1.1 \mathrm{~g})$ and stirred for 5 minutes. The resulting mixture was concentrated, and the residue was purified by $\mathrm{CC}(\mathrm{Rf}=0.40$, petroleum ether: ethyl acetate $=9: 1)$ to obtain $17(779.3 \mathrm{mg}$, 93\%). ${ }^{1} \mathrm{H}-\mathrm{NMR}\left(\mathrm{CDCl}_{3}, 400 \mathrm{MHz}\right) \delta 4.57(\mathrm{~d}, 1 \mathrm{H}, J=7.6 \mathrm{~Hz}$, $\left.\mathrm{C}^{1}-\mathrm{H}\right), 4.35$ (d, $2 \mathrm{H}, J=2.4 \mathrm{~Hz}, \mathrm{O}^{-\mathrm{CH}_{2}}$ ), 3.89-3.85 (m, $\left.1 \mathrm{H}\right)$,
3.71-3.66 (m, $1 \mathrm{H}), 3.54-3.43(\mathrm{~m}, 2 \mathrm{H}), 3.36-3.30(\mathrm{~m}$, $2 \mathrm{H}), 2.45$ (t, $1 \mathrm{H}, J=2.4 \mathrm{~Hz}, \mathrm{C} \equiv \mathrm{CH}), 0.90-0.88(\mathrm{~m}, 27 \mathrm{H})$, 0.15-0.11 (m, $18 \mathrm{H}) ;{ }^{13} \mathrm{C}-\mathrm{NMR}\left(\mathrm{CDCl}_{3}, 100 \mathrm{MHz}\right) \delta 101.2$ (C-1), $78.8(\mathrm{C} \equiv \mathrm{CH}), 78.0(\mathrm{C} \equiv \mathrm{CH}), 76.3,75.1,75.0,70.7$, $62.5(\mathrm{C}-6), 56.2\left(\mathrm{O}-\mathrm{CH}_{2}\right), 25.9\left(\mathrm{C}-\mathrm{CH}_{3}\right), 25.9\left(\mathrm{C}-\mathrm{CH}_{3}\right)$, $25.8\left({\mathrm{C}-\mathrm{CH}_{3}}_{3}\right), 18.2(\mathrm{Si}-\mathrm{C}), 18.2(\mathrm{Si}-\mathrm{C}), 18.2(\mathrm{Si}-\mathrm{C}),-3.9$ $\left(\mathrm{Si}-\mathrm{CH}_{3}\right),-3.9\left(\mathrm{Si}-\mathrm{CH}_{3}\right),-4.0\left(\mathrm{Si}-\mathrm{CH}_{3}\right),-4.7\left(\mathrm{Si}-\mathrm{CH}_{3}\right),-4.7$ $\left(\mathrm{Si}-\mathrm{CH}_{3}\right),-5.0\left(\mathrm{Si}_{-} \mathrm{CH}_{3}\right)$; ESIMS was calculated for $\mathrm{C}_{27} \mathrm{H}_{56} \mathrm{O}_{6-}$ $\mathrm{Si}_{3} \mathrm{Na}[\mathrm{M}+\mathrm{Na}]^{+} 583$ and was found to be 583 .

\section{Prop-2-yn-I-yl 6-0-(prop-2-yn-I-yl)- 2,3,4-tri-O-tert-butyldimethylsilyl- $\beta$-D- glucopyranoside ( I 8)}

A solution of $17(536.3 \mathrm{mg}, 1 \mathrm{mmol})$ in dry THF $(10 \mathrm{~mL})$ was added at $0^{\circ} \mathrm{C}$ to a suspension of $\mathrm{NaH}(60 \mathrm{mg}, 2.5 \mathrm{mmol})$ in dry THF $(3 \mathrm{~mL})$ under $\mathrm{N}_{2}$. The mixture was stirred at room temperature for 0.5 hour, then propargyl bromide $(1 \mathrm{~mL}$, $0.2 \mathrm{mmol})$ in THF $(5 \mathrm{~mL})$ was quickly added and the reaction mixture was refluxed overnight. The reaction mixture was quenched with water $(20 \mathrm{~mL})$, and then THF was removed in vacuo. The residue was extracted with $\mathrm{CH}_{2} \mathrm{Cl}_{2}(2 \times 20 \mathrm{~mL})$, and the organic layer was washed with brine $(20 \mathrm{~mL})$ and dried over $\mathrm{Na}_{2} \mathrm{SO}_{4}$, concentrated under reduced pressure. The residue was purified by $\mathrm{CC}(\mathrm{Rf}=0.50$, petroleum ether: ethyl acetate $=30: 1)$ to obtain $\mathbf{1 8}(299.2 \mathrm{mg}, 50 \%) .{ }^{1} \mathrm{H}-\mathrm{NMR}\left(\mathrm{CDCl}_{3}\right.$, $400 \mathrm{MHz}) 4.42\left(\mathrm{~d}, 1 \mathrm{H}, J=7.6 \mathrm{~Hz}, \mathrm{C}^{1}-\mathrm{H}\right), 4.37-4.35(\mathrm{~m}, 1 \mathrm{H})$, 4.24-4.19 (m, $\left.4 \mathrm{H}, 2 \times \mathrm{O}_{-} \mathrm{CH}_{2}\right), 3.87-3.84(\mathrm{~m}, 1 \mathrm{H}), 3.66-3.62$ (m, $1 \mathrm{H}), 3.55-3.50(\mathrm{~m}, 1 \mathrm{H}), 3.46-3.40(\mathrm{~m}, 1 \mathrm{H}), 3.36-3.32$ (m, $1 \mathrm{H}), 2.42-2.40(\mathrm{~m}, 2 \mathrm{H}, 2 \times \mathrm{C} \equiv \mathrm{CH}), 0.90-0.89(\mathrm{~m}, 27 \mathrm{H})$, $0.15-0.11(\mathrm{~m}, 18 \mathrm{H}) ;{ }^{13} \mathrm{C}-\mathrm{NMR}\left(\mathrm{CDCl}_{3}, 100 \mathrm{MHz}\right) \delta 100.3$ (C-1), $79.7(C \equiv \mathrm{CH}), 78.8(\mathrm{C} \equiv \mathrm{CH}), 78.2(\mathrm{C} \equiv \mathrm{CH}), 76.0,75.0$, 74.8, 74.6 (C $\equiv \mathrm{CH}), 70.7,68.8(\mathrm{C}-6), 58.6\left(\mathrm{CH}_{2}-\mathrm{C} \equiv \mathrm{CH}\right), 55.6$ $\left(\mathrm{CH}_{2}-\mathrm{C} \equiv \mathrm{CH}\right), 26.0\left(\mathrm{C}-\mathrm{CH}_{3}\right), 25.9\left(\mathrm{C}-\mathrm{CH}_{3}\right), 25.9\left(\mathrm{C}-\mathrm{CH}_{3}\right)$, $18.2(\mathrm{Si}-\mathrm{C}), 18.2(\mathrm{Si}-\mathrm{C}), 18.2(\mathrm{Si}-\mathrm{C})-3.8\left(\mathrm{Si}_{-} \mathrm{CH}_{3}\right),-3.9$ $\left(\mathrm{Si}-\mathrm{CH}_{3}\right),-4.0\left(\mathrm{Si}-\mathrm{CH}_{3}\right),-4.8\left(\mathrm{Si}-\mathrm{CH}_{3}\right),-4.7\left(\mathrm{Si}-\mathrm{CH}_{3}\right),-5.0$ $\left(\mathrm{Si}-\mathrm{CH}_{3}\right.$ ); ESIMS was calculated for $\mathrm{C}_{30} \mathrm{H}_{58} \mathrm{O}_{6} \mathrm{Si}{ }_{3} \mathrm{Na}[\mathrm{M}+\mathrm{Na}]^{+}$ 621 and was found to be 621 .

\section{Prop-2-yn- I-yl 6-0-(prop-2-yn-I-yl)- $\beta$-D- glucopyranoside (19)}

To a solution of $\mathbf{1 8}(119.7 \mathrm{mg}, 0.2 \mathrm{mmol})$ in dry THF (5 $\mathrm{mL})$, TBAF $(0.2 \mathrm{~mL}, 0.7 \mathrm{mmol})$ was added at room temperature. The mixture was stirred for 18 hours, and then the solvent was evaporated under reduced pressure and the crude product was purified by $\mathrm{CC}\left(\mathrm{Rf}=0.50, \mathrm{CHCl}_{3}\right.$ : $\left.\mathrm{CH}_{3} \mathrm{OH}=20: 1\right)$ to obtain the desired product $19(41.0 \mathrm{mg}$, $80 \%)$ as a colorless syrup. ${ }^{1} \mathrm{H}-\mathrm{NMR}\left(\left(\mathrm{CD}_{3}\right)_{2} \mathrm{SO}, 600 \mathrm{MHz}\right)$ 
5.97 (d, $\left.1 \mathrm{H}, J=7.6 \mathrm{~Hz}, \mathrm{C}^{1}-\mathrm{H}\right), 5.93-5.89$ (m, $\left.1 \mathrm{H}\right), 5.13-4.91$ (m, $2 \mathrm{H}), 4.56$ (dd, $1 \mathrm{H}, J=1.8 \mathrm{~Hz}, 11.4 \mathrm{~Hz}), 4.31-4.29$ (m, $1 \mathrm{H}), 4.00-3.97$ (m, $\left.4 \mathrm{H}, 2 \times \mathrm{O}_{-} \mathrm{CH}_{2}\right), 3.85-3.76(\mathrm{~m}, 1 \mathrm{H})$, 2.38-2.35 (m, $2 \mathrm{H}, 2 \times \mathrm{C} \equiv \mathrm{CH}) ;{ }^{13} \mathrm{C}-\mathrm{NMR}\left(\left(\mathrm{CD}_{3}\right)_{2} \mathrm{SO}, 150\right.$ $\mathrm{MHz}) \delta 100.8(\mathrm{C}-1), 80.5(C \equiv \mathrm{CH}), 79.8(C \equiv \mathrm{CH}), 77.4$ $(\mathrm{C} \equiv \mathrm{CH}), 77.1(\mathrm{C} \equiv \mathrm{CH}), 76.5,75.4,73.1,70.0,69.1(\mathrm{C}-6)$, $57.6\left(\mathrm{O}-\mathrm{CH}_{2}\right), 57.5\left(\mathrm{O}-\mathrm{CH}_{2}\right)$; ESIMS was calculated for $\mathrm{C}_{12} \mathrm{H}_{16} \mathrm{O}_{6} \mathrm{Na}[\mathrm{M}+\mathrm{Na}]^{+} 279$ and was found to be 279 .

\section{Prop-2-yn-I-yl 6-O-(prop-2-yn- I-yl)-2,3,4- tri-O-benzyl- $\beta$-D-glucopyranoside (20)}

Suspension (60\%) of $\mathrm{NaH}$ in paraffin $(28.0 \mathrm{mg}, 0.7 \mathrm{mmol})$ was added to a solution of $\mathbf{1 9}(51.2 \mathrm{mg}, 0.2 \mathrm{mmol})$ in anhydrous DMF $(3 \mathrm{~mL})$ at $0^{\circ} \mathrm{C}$ under argon atmosphere. The resulting solution was stirred for 30 minutes at room temperature. Benzyl bromide $(0.2 \mathrm{~mL}, 1.1 \mathrm{mmol})$ was added drop-wise at $0^{\circ} \mathrm{C}$ followed by a catalytic amount of tetra- $n$-butyl ammonium iodide $(20 \mathrm{mg})$. The resulting reaction mixture was stirred at room temperature under argon for 10 hours. After completion of the reaction (as judged by TLC), excess $\mathrm{NaH}$ was quenched with methanol $(0.5 \mathrm{~mL})$ followed by ice water $(10 \mathrm{~mL})$ and extracted with ether $(3 \times 10 \mathrm{~mL})$. The combined organic layer was washed with water, brine, dried over anhydrous $\mathrm{Na}_{2} \mathrm{SO}_{4}$ and concentrated in vacuo. The crude residue was purified by $\mathrm{CC}(\mathrm{Rf}=0.20$, petroleum ether: ethyl acetate $=30: 1)$ to obtain $\mathbf{2 0}$ (73.6 mg, 70\%). ${ }^{1} \mathrm{H}-\mathrm{NMR}\left(\mathrm{CDCl}_{3}, 400 \mathrm{MHz}\right) \delta 7.38-7.26(\mathrm{~m}$, $15 \mathrm{H}, \mathrm{Ar}-\mathrm{H}), 4.99-4.92(\mathrm{~m}, 1 \mathrm{H}), 4.88-4.79$ (m, $1 \mathrm{H}), 4.70-4.64$ (m, $\left.6 \mathrm{H}, 3 \times \mathrm{O}-\mathrm{CH}_{2}\right), 4.45\left(\mathrm{~d}, 1 \mathrm{H}, J=6.8 \mathrm{~Hz}, \mathrm{C}^{1}-\mathrm{H}\right), 4.43-4.40$ $(\mathrm{m}, 1 \mathrm{H}), 4.27-4.15(\mathrm{~m}, 1 \mathrm{H}), 3.86-3.82(\mathrm{~m}, 1 \mathrm{H}), 3.78-3.75(\mathrm{~m}$, $1 \mathrm{H}), 3.70-3.61$ (m, $\left.2 \mathrm{H}, \mathrm{O}-\mathrm{CH}_{2}\right), 3.50-3.46\left(\mathrm{~m}, 2 \mathrm{H}, \mathrm{O}-\mathrm{CH}_{2}\right)$, 2.47 (s, $1 \mathrm{H}, \mathrm{C} \equiv \mathrm{CH}), 2.39$ (s, $1 \mathrm{H}, \mathrm{C} \equiv \mathrm{CH}) ;{ }^{13} \mathrm{C}-\mathrm{NMR}\left(\mathrm{CDCl}_{3}\right.$, $100 \mathrm{MHz}) \delta 138.6,138.3,138.1,128.5,128.4,128.4,128.4$, $128.3,128.2,128.1,128.0,127.9,127.8,127.8,127.7,127.6$, $101.4(\mathrm{C}-1), 84.5,81.9,79.6(C \equiv \mathrm{CH}), 79.0(C \equiv \mathrm{CH}), 75.7,75.0$, 74.9, $74.8(\mathrm{C} \equiv C \mathrm{H}), 74.8(\mathrm{C} \equiv C \mathrm{H}), 68.1(\mathrm{C}-6), 58.6\left(\mathrm{O}-\mathrm{CH}_{2}\right)$, $56.0\left(\mathrm{O}-\mathrm{CH}_{2}\right)$; ESIMS was calculated for $\mathrm{C}_{33} \mathrm{H}_{34} \mathrm{O}_{6} \mathrm{Na}[\mathrm{M}+\mathrm{Na}]^{+}$ 549 and was found to be 549 .

\section{Prop-2-yn-I-yl 6-O-(prop-2-yn-I-yl)-2,3,4- tri-O-acetyl- $\beta$-D-glucopyranoside (2 I )}

To a solution of $\mathbf{2 0}(51.2 \mathrm{mg}, 0.2 \mathrm{mmol})$ in pyridine $(2 \mathrm{~mL})$ at $0^{\circ} \mathrm{C}$, acetic anhydride $(0.2 \mathrm{~mL}, 2 \mathrm{mmol})$ was added. The reaction mixture was stirred at room temperature for 12 hours (TLC monitoring). The reaction mixture was diluted with water $(20 \mathrm{~mL})$ and extracted with ethyl acetate $(3 \times 10 \mathrm{~mL})$. The organic layer was washed with $10 \%$ aqueous hydrochloric acid $(10 \mathrm{~mL})$ and brine $(10 \mathrm{~mL})$. The organic layer was dried over $\mathrm{Na}_{2} \mathrm{SO}_{4}$ and evaporated to give a residue, which was purified by $\mathrm{CC}(\mathrm{Rf}=0.20$, petroleum ether: ethyl acetate=4:1) to obtain 21 (69.5 mg, 91\%). ${ }^{1} \mathrm{H}-\mathrm{NMR}$ $\left(\mathrm{CDCl}_{3}, 400 \mathrm{MHz}\right) \delta 4.78(\mathrm{t}, 1 \mathrm{H}, J=9.4 \mathrm{~Hz}), 4.66(\mathrm{~d}, 1 \mathrm{H}$, $\left.J=8.0 \mathrm{~Hz}, \mathrm{C}^{1}-\mathrm{H}\right), 4.37-4.36$ (m, $\left.2 \mathrm{H}\right), 4.24-4.20$ (m, $\left.2 \mathrm{H}\right)$, 3.87 (dd, $1 \mathrm{H}, J=1.7 \mathrm{~Hz}, 10.8 \mathrm{~Hz}), 3.68-3.43$ (m, $4 \mathrm{H}, 2 \times$ $\left.\mathrm{O}-\mathrm{CH}_{2}\right), 2.43-2.42(\mathrm{~m}, 2 \mathrm{H}, 2 \times \mathrm{C} \equiv \mathrm{CH}), 2.15-2.10(\mathrm{~m}, 9 \mathrm{H}$, $\left.3 \times \mathrm{COCH}_{3}\right) ;{ }^{13} \mathrm{C}-\mathrm{NMR}\left(\mathrm{CDCl}_{3}, 100 \mathrm{MHz}\right) \delta 171.0(\mathrm{C}=\mathrm{O})$, $169.9(\mathrm{C}=\mathrm{O}), 169.8(\mathrm{C}=\mathrm{O}), 100.4(\mathrm{C}-1), 79.5(\mathrm{C} \equiv \mathrm{CH}), 78.7$ $(C \equiv \mathrm{CH}), 76.2(\mathrm{C} \equiv \mathrm{CH}), 76.0(\mathrm{C} \equiv C \mathrm{H}), 74.9,74.7,73.9,71.9$, $68.5(\mathrm{C}-6), 58.7\left(\mathrm{O}-\mathrm{CH}_{2}\right), 55.6\left(\mathrm{O}-\mathrm{CH}_{2}\right), 25.9\left(\mathrm{COCH}_{3}\right)$, $25.9\left(\mathrm{COCH}_{3}\right), 25.8\left(\mathrm{COCH}_{3}\right)$; ESIMS was calculated for $\mathrm{C}_{18} \mathrm{H}_{22} \mathrm{O}_{9} \mathrm{Na}[\mathrm{M}+\mathrm{Na}]^{+} 405$ and found to be 405 .

\section{Prop-2-yn- I-yl 6-O-(prop-2-yn- I-yl)-2,3,4- tri-O-butyryl- $\beta$-D-glucopyranoside (22)}

Butyryl anhydride $(0.3 \mathrm{~mL}, 2 \mathrm{mmol})$ was added to a solution of $20(51.2 \mathrm{mg}, 0.2 \mathrm{mmol})$ in pyridine $(2 \mathrm{~mL})$ at $0^{\circ} \mathrm{C}$. The reaction mixture was stirred at room temperature for 12 hours. The reaction mixture was diluted with water $(20 \mathrm{~mL})$ and extracted with ethyl acetate $(3 \times 10 \mathrm{~mL})$. The organic layer was washed with $10 \%$ aqueous hydrochloric acid $(10 \mathrm{~mL})$ and brine $(10 \mathrm{~mL})$. The organic layer was dried over $\mathrm{Na}_{2} \mathrm{SO}_{4}$ and evaporated to give a residue, which was purified by $\mathrm{CC}$ $(\mathrm{Rf}=0.20$, petroleum ether: ethyl acetate $=10: 1)$ to obtain 22 (86.7 mg, 93\%). ${ }^{1} \mathrm{H}-\mathrm{NMR}\left(\mathrm{CDCl}_{3}, 400 \mathrm{MHz}\right) \delta 4.92(\mathrm{t}, 1 \mathrm{H}$, $J=9.3 \mathrm{~Hz}), 4.47$ (d, $\left.1 \mathrm{H}, J=8.0 \mathrm{~Hz}, \mathrm{C}^{1}-\mathrm{H}\right), 4.38-4.36(\mathrm{~m}, 2 \mathrm{H})$, 4.19-4.17 (m, 3 H), 3.65-3.44 (m, 4 H, 2× O-CH H $_{2}, 2.43-$ $2.41(\mathrm{~m}, 2 \mathrm{H}, 2 \times \mathrm{C} \equiv \mathrm{CH}), 2.36-2.32\left(\mathrm{~m}, 6 \mathrm{H}, 3 \times \mathrm{COCH}_{2}\right)$, 1.70-1.63 (m, 6 H, 3× $\left.\mathrm{CH}_{2} \mathrm{CH}_{3}\right), 0.98-0.89(\mathrm{~m}, 9 \mathrm{H}, 3 \times$ $\left.\mathrm{CH}_{2} \mathrm{CH}_{3}\right) ;{ }^{13} \mathrm{C}-\mathrm{NMR}\left(\mathrm{CDCl}_{3}, 100 \mathrm{MHz}\right) \delta 173.2(\mathrm{C}=\mathrm{O})$, $173.2(\mathrm{C}=\mathrm{O}), 173.1(\mathrm{C}=\mathrm{O}), 100.4(\mathrm{C}-1), 79.3(\mathrm{C} \equiv \mathrm{CH}), 78.6$ $(C \equiv \mathrm{CH}), 76.7(\mathrm{C} \equiv C \mathrm{H}), 76.2(\mathrm{C} \equiv C H), 75.2,74.9,73.3,71.9$, $68.7(\mathrm{C}-6), 58.7\left(\mathrm{O}-\mathrm{CH}_{2}\right), 55.8\left(\mathrm{O}-\mathrm{CH}_{2}\right), 36.2\left(\mathrm{COCH}_{2}\right), 36.2$ $\left(\mathrm{COCH}_{2}\right), 36.1\left(\mathrm{COCH}_{2}\right), 18.4\left(\mathrm{CH}_{2} \mathrm{CH}_{3}\right), 18.2\left(\mathrm{CH}_{2} \mathrm{CH}_{3}\right)$, $18.2\left(\mathrm{CH}_{2} \mathrm{CH}_{3}\right), 13.7\left(\mathrm{CH}_{2} \mathrm{CH}_{3}\right), 13.6\left(\mathrm{CH}_{2} \mathrm{CH}_{3}\right), 13.6$ $\left(\mathrm{CH}_{2} \mathrm{CH}_{3}\right)$; ESIMS was calculated for $\mathrm{C}_{24} \mathrm{H}_{34} \mathrm{O}_{9} \mathrm{Na}[\mathrm{M}+\mathrm{Na}]^{+}$ 489 and was found to be 489 .

\section{Click reaction - general procedure for the preparation of dimeric podophyllotoxin derivatives 25-40}

Copper (II) sulfate pentahydrate $(0.01 \mathrm{mmol})$ and sodium ascorbate $\left(1.0 \mathrm{M}\right.$ in $\left.\mathrm{H}_{2} \mathrm{O}, 3 \mathrm{~d}\right)$ were added to a solution of a terminal-alkyne 10, 12-14, or 19-22 $(0.1 \mathrm{mmol})$ and a $4 \beta$-azido-podophyllotoxin analog 23 or $24^{28}(0.1 \mathrm{mmol})$ in $t-\mathrm{BuOH}_{-} \mathrm{H}_{2} \mathrm{O}(1: 1,1 \mathrm{~mL})$ at room temperature. The reaction mixture was stirred at room temperature for 4 hours until the starting material disappeared as indicated by TLC. Then, the 
mixture was diluted with water $(10 \mathrm{~mL})$ and extracted with ethyl acetate $(3 \times 10 \mathrm{~mL})$, and the combined organic layer was dried over $\mathrm{Na}_{2} \mathrm{SO}_{4}$. The solvent was evaporated and the residue was purified by $\mathrm{CC}$ to obtain the cycloaddition product.

\section{I,3-Di-[I-(4-deoxypodophyllotoxin- 4/-yl)-I,2,3-triazol-4-yl-methoxy]- propan-2-ol (25)}

$\mathrm{Rf}=0.60\left(\mathrm{CHCl}_{3}: \mathrm{CH}_{3} \mathrm{OH}=30: 1\right)$. White amorphous powder, yield $86 \%$; mp. $164^{\circ} \mathrm{C}-166^{\circ} \mathrm{C}\left(\mathrm{CH}_{2} \mathrm{Cl}_{2}\right) ;[\alpha]_{\mathrm{D}}{ }^{23.4}:-117.9$ (c 0.28 , Pyridine); ${ }^{1} \mathrm{H}-\mathrm{NMR}\left(\mathrm{CDCl}_{3}, 400 \mathrm{MHz}\right) \delta 7.35$ $(\mathrm{s}, 1 \mathrm{H}), 7.32(\mathrm{~s}, 1 \mathrm{H}), 6.62-6.61(\mathrm{~m}, 4 \mathrm{H}), 6.31(\mathrm{~s}, 4 \mathrm{H})$, 6.08-5.99 (m, 6 H), 4.75-4.71 (m, 2 H), 4.68-4.60 (m, 6 H), 4.38-4.35 (m, 2 H), $3.81(\mathrm{~s}, 6 \mathrm{H}), 3.76$ (s, $12 \mathrm{H}), 3.70-3.69$ (s, 1 H), 3.64-3.60 (m, 4 H), 3.24-3.22 (m, $2 \mathrm{H}), 3.14-3.11$ $(\mathrm{m}, 2 \mathrm{H}) ;{ }^{13} \mathrm{C}-\mathrm{NMR}\left(\mathrm{CDCl}_{3}, 100 \mathrm{MHz}\right) \delta 173.2,152.8,149.4$, 148.0, 145.4, 145.0, 137.5, 134.3, 133.2, 124.6, 123.0, 110.5, 108.8, 108.1, 102.0, 79.1, 70.3, 70.1, 67.4, 60.7, 58.7, 56.3, 43.6, 41.5, 37.1; ESIMS: m/z $1069[\mathrm{M}+\mathrm{Na}]^{+}$, HRESIMS was calculated for $\mathrm{C}_{53} \mathrm{H}_{54} \mathrm{~N}_{6} \mathrm{NaO}_{17}[\mathrm{M}+\mathrm{Na}]^{+} 1069.3443$ and was found to be 1069.3437 .

\section{I,3-Di-[I-(4-deoxy-4'-}

demethylpodophyllotoxin-4 $\beta-y \mid)-I, 2,3-$ triazol-4-yl-methoxy]-propan-2-ol (26)

$\mathrm{Rf}=0.40\left(\mathrm{CHCl}_{3}: \mathrm{CH}_{3} \mathrm{OH}=30: 1\right)$. White amorphous powder, yield $82 \%$; mp. $190^{\circ} \mathrm{C}-192^{\circ} \mathrm{C}\left(\mathrm{CH}_{3} \mathrm{OH}\right) ;[\alpha]_{\mathrm{D}}^{23.5}:-200.6$ (c 0.11 , Pyridine); ${ }^{1} \mathrm{H}-\mathrm{NMR}\left(\mathrm{C}_{2} \mathrm{D}_{6} \mathrm{SO}, 400 \mathrm{MHz}\right) \delta 7.96$ $(\mathrm{s}, 1 \mathrm{H}), 7.95(\mathrm{~s}, 1 \mathrm{H}), 6.73(\mathrm{~s}, 2 \mathrm{H}), 6.64(\mathrm{~s}, 2 \mathrm{H}), 6.25$ $(\mathrm{s}, 4 \mathrm{H}), 6.22(\mathrm{~d}, 2 \mathrm{H}, J=5.2 \mathrm{~Hz}), 6.02-5.96(\mathrm{~m}, 4 \mathrm{H})$, 4.67-4.64 (m, 2 H), 4.62-4.58 (m, $4 \mathrm{H}), 4.48-4.47$ (m, $2 \mathrm{H})$, 4.36-4.33 (m, $2 \mathrm{H}), 3.63(\mathrm{~s}, 12 \mathrm{H}), 3.53-3.26(\mathrm{~m}, 5 \mathrm{H})$, 3.24-3.18 (m, $2 \mathrm{H}), 2.95-2.91$ (m, $2 \mathrm{H}) ;{ }^{13} \mathrm{C}-\mathrm{NMR}\left(\mathrm{C}_{2} \mathrm{D}_{6} \mathrm{SO}\right.$, $100 \mathrm{MHz}) \delta 173.7,148.1,147.3,146.9,144.5,143.9,134.9$, 133.3, 129.7, 126.1, 124.7, 124.6, 109.9, 108.7, 108.4, 101.6, 78.7, 69.6, 67.2, 60.7, 57.5, 56.0, 42.8, 40.9, 36.5; ESIMS: $m / z$ $1041[\mathrm{M}+\mathrm{Na}]^{+}$, HRESIMS was calculated for $\mathrm{C}_{51} \mathrm{H}_{50} \mathrm{~N}_{6} \mathrm{NaO}_{17}$ $[\mathrm{M}+\mathrm{Na}]^{+} 1041.3130$ and was found to be 1041.3127 .

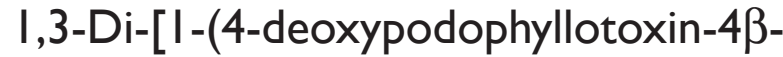
yl)-I,2,3-triazol-4-yl-methoxy]-prop-2-yl $\beta$-D-glucopyranoside (27)

$\mathrm{Rf}=0.50\left(\mathrm{CHCl}_{3}: \mathrm{CH}_{3} \mathrm{OH}=9: 1\right)$. White amorphous powder, yield $76 \%$; mp. $140^{\circ} \mathrm{C}-142^{\circ} \mathrm{C}\left(\mathrm{CH}_{2} \mathrm{Cl}_{2}\right) ;[\alpha]_{\mathrm{D}}{ }^{23.6}:-53.7$ (c $\left.0.19, \mathrm{CHCl}_{3}\right) ;{ }^{1} \mathrm{H}-\mathrm{NMR}\left(\mathrm{CDCl}_{3}, 400 \mathrm{MHz}\right) \delta 7.49$ (s, 1 hour), 7.41 (s, 1 H), 6.59-6.58 (m, $2 \mathrm{H}), 6.55(\mathrm{~m}, 2 \mathrm{H})$, $6.30(\mathrm{~s}, 4 \mathrm{H}), 6.04-5.93(\mathrm{~m}, 6 \mathrm{H}), 4.71-4.67(\mathrm{~m}, 5 \mathrm{H})$, 4.53-4.50 (m, 2 H), 4.33-4.29 (m, 4 H), 3.95-3.92 (m, $1 \mathrm{H})$,
3.77 (s, $6 \mathrm{H}), 3.74$ (s, $12 \mathrm{H}), 3.65-3.52$ (m, $9 \mathrm{H}), 3.37-3.18$ $(\mathrm{m}, 5 \mathrm{H}) ;{ }^{13} \mathrm{C}-\mathrm{NMR}\left(\mathrm{CDCl}_{3}, 100 \mathrm{MHz}\right) \delta 173.6,173.5,152.7$, 149.2, 147.9, 144.8, 144.5, 137.3, 134.4, 133.2, 124.8, 110.4, $108.8,108.1,103.2,102.0,77.2,76.4,75.9,73.4,69.7,67.5$, 64.3, 64.2, 62.6, 61.5, 60.7, 58.6, 56.3, 43.6, 41.4, 37.0; ESIMS: $m / z 1209[\mathrm{M}+\mathrm{H}]^{+}$, HRESIMS was calculated for $\mathrm{C}_{59} \mathrm{H}_{64} \mathrm{~N}_{6} \mathrm{NaO}_{22}[\mathrm{M}+\mathrm{Na}]^{+} 1231.3971$ and was found to be 1231.3962 .

\section{I,3-Di-[I-(4-deoxypodophyllotoxin- 4/-yl)- I,2,3-triazol-4-yl-methoxy]- prop-2-yl 2,3,4,6-tera-O-acetyl- $\beta$-D- glucopyranoside (28)}

$\mathrm{Rf}=0.50\left(\mathrm{CHCl}_{3}: \mathrm{CH}_{3} \mathrm{OH}=30: 1\right)$. White amorphous powder, yield $80 \%$; mp. $140^{\circ} \mathrm{C}-142^{\circ} \mathrm{C}\left(\mathrm{CH}_{2} \mathrm{Cl}_{2}\right) ;[\alpha]_{\mathrm{D}}{ }^{23.8}:-42.9$ (c $\left.0.14, \mathrm{CHCl}_{3}\right) ;{ }^{1} \mathrm{H}-\mathrm{NMR}\left(\mathrm{CDCl}_{3}, 400 \mathrm{MHz}\right) \delta 7.44$ (s, $1 \mathrm{H}), 7.35(\mathrm{~s}, 1 \mathrm{H}), 6.63(\mathrm{~s}, 2 \mathrm{H}), 6.62-6.61(\mathrm{~m}, 2 \mathrm{H})$, 6.32 (s, $4 \mathrm{H}), 6.08$ (d, $2 \mathrm{H}, J=2.0 \mathrm{~Hz}), 6.01-6.00$ (m, $4 \mathrm{H})$, 5.90 (d, $1 \mathrm{H}, J=7.2 \mathrm{~Hz}), 5.22-5.17$ (m, $1 \mathrm{H}), 5.11-5.09$ (m, $1 \mathrm{H}), 5.00-4.96(\mathrm{~m}, 1 \mathrm{H}), 4.76-4.73$ (m, $4 \mathrm{H}), 4.71-4.66$ (m, 2 H), 4.58-4.52 (m, 3 H), 4.39-4.25 (m, 3 H), 4.15-4.11 (m, 1 H), 3.94-3.91 (m, 1 H), $3.81(\mathrm{~s}, 6 \mathrm{H}), 3.77(\mathrm{~s}, 12 \mathrm{H})$, 3.65-3.58 (m, 4 H), 3.31-3.21 (m, 4 H), 2.07-2.01 (m, $12 \mathrm{H}$, $\left.4 \times \mathrm{COCH}_{3}\right) ;{ }^{13} \mathrm{C}-\mathrm{NMR}\left(\mathrm{CDCl}_{3}, 100 \mathrm{MHz}\right) \delta 173.3,173.2$, 170.6, 170.2, 169.5, 169.5, 152.8, 149.3, 148.0, 145.2, 144.9, $137.5,134.3,133.2,124.7,123.2,110.5,108.8,108.2,101.9$, $100.9,77.2,72.6,71.8,71.2,70.2,68.3,67.4,64.7,61.8,60.8$, 58.6, 56.2, 43.4, 41.5, 37.1, $20.8\left(\mathrm{COCH}_{3}\right), 20.7\left(\mathrm{COCH}_{3}\right)$, $20.7\left(\mathrm{COCH}_{3}\right), 20.6\left(\mathrm{COCH}_{3}\right)$; ESIMS: $m / z 1377[\mathrm{M}+\mathrm{H}]^{+}$, HRESIMS was calculated for $\mathrm{C}_{67} \mathrm{H}_{72} \mathrm{~N}_{6} \mathrm{NaO}_{26}[\mathrm{M}+\mathrm{Na}]^{+}$ 1399.4394 and was found to be 1399.4391 .

\section{I,3-Di-[I-(4-deoxypodophyllotoxin- 4(3-yl)-I,2,3-triazol-4-yl-methoxy]- prop-2-yl 2,3,4,6-tera-O-butyryl- $\beta$-D- glucopyranoside (29)}

$\mathrm{Rf}=0.30$ (petroleum ether: ethyl acetate $=1: 3$ ). White amorphous powder, yield $78 \%$; mp $110^{\circ} \mathrm{C}-112^{\circ} \mathrm{C}\left(\mathrm{CH}_{2} \mathrm{Cl}_{2}\right)$; $[\alpha]_{\mathrm{D}}{ }^{23.8}:-40.1\left(\mathrm{c} 0.22, \mathrm{CHCl}_{3}\right) ;{ }^{1} \mathrm{H}-\mathrm{NMR}\left(\mathrm{CDCl}_{3}, 400 \mathrm{MHz}\right) \delta$ 7.44 (s, 1 H), 7.37 (s, $1 \mathrm{H}), 6.63$ (s, $2 \mathrm{H}), 6.61$ (s, $2 \mathrm{H}), 6.32$ (s, $4 \mathrm{H}), 6.08-5.99$ (m, $6 \mathrm{H}), 5.88$ (d, $1 \mathrm{H}, J=3.2 \mathrm{~Hz}), 5.25-5.21$ (m, 1 H), 5.14-5.08 (m, 1 H), 5.02-4.95 (m, 1 H), 4.79-4.76 $(\mathrm{m}, 4 \mathrm{H}), 4.72-4.66(\mathrm{~m}, 2 \mathrm{H}), 4.57-4.51(\mathrm{~m}, 3 \mathrm{H})$, 4.38-4.31 (m, 2 H), 4.21-4.17 (m, $2 \mathrm{H}), 3.91-3.88$ (m, $1 \mathrm{H})$, $3.81(\mathrm{~s}, 6 \mathrm{H}), 3.76(\mathrm{~s}, 12 \mathrm{H}), 3.63-3.57$ (m, $4 \mathrm{H}), 3.54-3.48$ (m, $2 \mathrm{H}), 3.31-3.21(\mathrm{~m}, 2 \mathrm{H}), 2.30-2.18\left(\mathrm{~m}, 8 \mathrm{H}, 4 \times \mathrm{COCH}_{2}\right)$, 1.63-1.53 (m, 8 H, 4× $\left.\mathrm{CH}_{2} \mathrm{CH}_{3}\right), 0.92-0.87(\mathrm{~m}, 12 \mathrm{H}$, 
$\left.4 \times \mathrm{CH}_{2} \mathrm{CH}_{3}\right) ;{ }^{13} \mathrm{C}-\mathrm{NMR}\left(\mathrm{CDCl}_{3}, 100 \mathrm{MHz}\right) \delta 173.2(2 \mathrm{C})$, 172.6, 172.4, 172.0, 172.0, 152.7 (2C), 149.3, 148.0, 145.3, $145.2,137.5,134.3,133.0,124.7,123.2,110.5,108.8,108.2$, $101.9,100.7,77.2,72.2,72.0,71.0,68.0,67.3,64.7,61.7,60.7$, $56.3,56.0,43.6,41.5,37.1,35.9\left(\mathrm{COCH}_{2}\right), 35.8\left(\mathrm{COCH}_{2}\right), 35.7$ $\left(\mathrm{COCH}_{2}\right), 18.3\left(\mathrm{CH}_{2} \mathrm{CH}_{3}\right), 18.2\left(\mathrm{CH}_{2} \mathrm{CH}_{3}\right), 18.1\left(\mathrm{CH}_{2} \mathrm{CH}_{3}\right)$, $13.6\left(\mathrm{CH}_{2} \mathrm{CH}_{3}\right), 13.5\left(\mathrm{CH}_{2} \mathrm{CH}_{3}\right), 13.5\left(\mathrm{CH}_{2} \mathrm{CH}_{3}\right)$; ESIMS: $m / z$ $1489[\mathrm{M}+\mathrm{H}]^{+}$, HRESIMS was calculated for $\mathrm{C}_{75} \mathrm{H}_{88} \mathrm{~N}_{6} \mathrm{NaO}_{26}$ $[\mathrm{M}+\mathrm{Na}]^{+} 1511.5646$ and was found to be 1511.5639 .

\section{I,3-Di-[I-(4-deoxy-4'-}

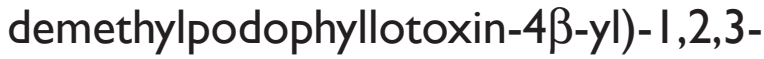
triazol-4-yl-methoxy]-prop-2-yl $\beta$-Dglucopyranoside (30)

$\mathrm{Rf}=0.40\left(\mathrm{CHCl}_{3}: \mathrm{CH}_{3} \mathrm{OH}=9: 1\right)$. White amorphous powder, yield $79 \%$; mp $173^{\circ} \mathrm{C}-174^{\circ} \mathrm{C}\left(\mathrm{CHCl}_{3}\right) ;[\alpha]_{\mathrm{D}}^{23.3}:-60.0$ (c 0.14 , $\left.\mathrm{CH}_{3} \mathrm{OH}+\mathrm{CHCl}_{3}\right) ;{ }^{1} \mathrm{H}-\mathrm{NMR}\left(\mathrm{CDCl}_{3}, 400 \mathrm{MHz}\right) \delta 7.44(\mathrm{~s}, 1 \mathrm{H})$, $7.36(\mathrm{~s}, 1 \mathrm{H}), 6.56-6.55(\mathrm{~m}, 2 \mathrm{H}), 6.54(\mathrm{~s}, 2 \mathrm{H}), 6.26(\mathrm{~s}$, $4 \mathrm{H}), 6.03-5.92$ (m, $6 \mathrm{H}), 4.69-4.66$ (m, $5 \mathrm{H}), 4.52$ (d, $2 \mathrm{H}$, $J=4.0 \mathrm{~Hz}), 4.31-4.27$ (m, $2 \mathrm{H}), 4.24-4.19$ (m, $2 \mathrm{H}), 3.93-3.90$ $(\mathrm{m}, 1 \mathrm{H}), 3.80-3.77(\mathrm{~m}, 2 \mathrm{H}), 3.72(\mathrm{~s}, 12 \mathrm{H}), 3.64-3.54$ $(\mathrm{m}, 7 \mathrm{H}), 3.36-3.18(\mathrm{~m}, 5 \mathrm{H}) ;{ }^{13} \mathrm{C}-\mathrm{NMR}\left(\mathrm{CDCl}_{3}, 100 \mathrm{MHz}\right) \delta$ 173.9, 173.8, 149.3, 147.9, 146.7, 144.8, 144.6, 134.4, 133.4, $129.6,124.6,123.6,110.4,108.76,107.8,101.3,101.9,77.2$, 76.2, 75.9, 73.4, 73.3, 69.9, 67.4, 64.4, 63.2, 58.7, 56.4, 43.3, 41.5, 36.9; ESIMS: $m / z 1181[\mathrm{M}+\mathrm{H}]^{+}$, HRESIMS was calculated for $\mathrm{C}_{57} \mathrm{H}_{60} \mathrm{~N}_{6} \mathrm{NaO}_{22}[\mathrm{M}+\mathrm{Na}]^{+} 1203.3658$ and was found to be 1203.3637 .

\section{I,3-Di-[I-(4-deoxy-4'-}

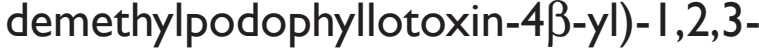
triazol-4-yl-methoxy]-prop-2-yl 2,3,4,6tera-O-acetyl- $\beta$-D-glucopyranoside (3 I)

$\mathrm{Rf}=0.50\left(\mathrm{CHCl}_{3}: \mathrm{CH}_{3} \mathrm{OH}=15: 1\right)$. White amorphous powder, yield $81 \%$; mp $158^{\circ} \mathrm{C}-160^{\circ} \mathrm{C}\left(\mathrm{CHCl}_{3}\right) ;[\alpha]_{\mathrm{D}}^{23.2}$ : -49.7 (c 0.15 , $\left.\mathrm{CHCl}_{3}\right) ;{ }^{1} \mathrm{H}-\mathrm{NMR}\left(\mathrm{CDCl}_{3}, 400 \mathrm{MHz}\right) \delta 7.52(\mathrm{~s}, 1 \mathrm{H}), 7.41$ (s, $1 \mathrm{H}), 6.65-6.64(\mathrm{~m}, 2 \mathrm{H}), 6.37-6.35(\mathrm{~m}, 6 \mathrm{H}), 6.10$ (d, $2 \mathrm{H}, J=4.2 \mathrm{~Hz}), 6.04-6.03$ (m, $4 \mathrm{H}), 6.00$ (d, $1 \mathrm{H} J=7.2 \mathrm{~Hz}$ ), 5.24-5.20 (m, $1 \mathrm{H}), 5.15-5.00(\mathrm{~m}, 1 \mathrm{H}), 5.02-4.96(\mathrm{~m}, 1 \mathrm{H})$, 4.79-4.70 (m, 6 H), 4.60-4.55 (m, 3 H), 4.40-4.37 (m, $1 \mathrm{H})$, 4.32-4.27 (m, 2 H), 4.17-4.15 (m, 1 H), 3.96-3.92 (m, $1 \mathrm{H})$, $3.78-3.70$ (m, 2 H), 3.66-3.60 (m, 2 H), 3.27-3.20 (m, 4 H), 2.09-2.03 (m, $\left.12 \mathrm{H}, 4 \times \mathrm{COCH}_{3}\right) ;{ }^{13} \mathrm{C}-\mathrm{NMR}$ (CD $\mathrm{OD}, 100$ $\mathrm{MHz}) \delta 173.4,173.3,170.7,170.3,169.5,169.5,149.3$, $147.9,146.6,145.2,144.9,134.4,133.4,130.0,124.7$, $123.3,110.5,108.8,107.8,101.9,100.9,77.0,72.6,71.9$, $71.2,70.2,70.1,68.3,67.4,64.8,61.8,58.7,56.6,43.5$,
41.7, 37.1, $20.8\left(\mathrm{COCH}_{3}\right), 20.7\left(\mathrm{COCH}_{3}\right), 20.6\left(\mathrm{COCH}_{3}\right)$, $20.6\left(\mathrm{COCH}_{3}\right)$; ESIMS: $m / z 1349[\mathrm{M}+\mathrm{H}]^{+}$, HRESIMS was calculated for $\mathrm{C}_{65} \mathrm{H}_{68} \mathrm{~N}_{6} \mathrm{NaO}_{26}[\mathrm{M}+\mathrm{Na}]^{+} 1371.4081$ and was found to be 1371.4072 .

\section{I,3-Di-[I-(4-deoxy-4'-}

demethylpodophyllotoxin-4ß-yl)-I,2,3triazol-4-yl-methoxy]-prop-2-yl 2,3,4,6tera-O-butyryl- $\beta$-D-glucopyranoside (32)

$\mathrm{Rf}=0.20$ (petroleum ether: ethyl acetate $=1: 3$ ). White amorphous powder, yield $78 \%$; mp $138^{\circ} \mathrm{C}-139^{\circ} \mathrm{C}\left(\mathrm{CH}_{2} \mathrm{Cl}_{2}\right)$; $[\alpha]_{\mathrm{D}}{ }^{23.8}:-50.8\left(\mathrm{c} 0.14, \mathrm{CHCl}_{3}\right) ;{ }^{1} \mathrm{H}-\mathrm{NMR}\left(\mathrm{CDCl}_{3}, 400 \mathrm{MHz}\right)$ $\delta 7.52(\mathrm{~s}, 1 \mathrm{H}), 7.40(\mathrm{~s}, 1 \mathrm{H}), 6.62(\mathrm{~s}, 2 \mathrm{H}), 6.61(\mathrm{~s}, 2 \mathrm{H})$, $6.33(\mathrm{~s}, 4 \mathrm{H}), 6.07-5.97(\mathrm{~m}, 7 \mathrm{H}), 5.26-5.21(\mathrm{~m}, 1 \mathrm{H})$, 5.16-5.12 (m, 1 H), 5.02-4.96 (m, 1 H), 4.78-4.73 (m, $4 \mathrm{H}), 4.70-4.68$ (m, $2 \mathrm{H}), 4.57-4.51$ (m, $3 \mathrm{H}), 4.36-4.28$ (m, $2 \mathrm{H}), 4.21-4.17$ (m, $2 \mathrm{H}), 3.92-3.88$ (m, $1 \mathrm{H}), 3.80$ (s, $12 \mathrm{H}), 3.74-3.69$ (m, $2 \mathrm{H}), 3.61-3.58$ (m, $2 \mathrm{H}), 3.54-3.47$ (m, $2 \mathrm{H}), 3.32-3.27$ (m, $2 \mathrm{H}), 2.31-2.20\left(\mathrm{~m}, 8 \mathrm{H}, 4 \times \mathrm{COCH}_{2}\right)$, 1.65-1.53 (m, 8 H, 4× $\left.\mathrm{CH}_{2} \mathrm{CH}_{3}\right), 0.92-0.87(\mathrm{~m}, 12 \mathrm{H}, 4 \times$ $\left.\mathrm{CH}_{2} \mathrm{CH}_{3}\right) ;{ }^{13} \mathrm{C}-\mathrm{NMR}\left(\mathrm{CDCl}_{3}, 100 \mathrm{MHz}\right) \delta 173.2,172.3$, 172.1, 172.0, 172.0, 148.2, 148.0, 146.6, 145.1, 145.0, 134.3, $133.4,129.8,124.7,123.2,110.5,108.8,107.8,101.9,100.4$ $77.2,72.2,72.1,71.0,68.0,67.3,65.2,64.7,61.7,58.6,56.5$, 43.5, 41.6, 37.0, 36.5, $36.0\left(\mathrm{COCH}_{2}\right), 35.9\left(\mathrm{COCH}_{2}\right), 35.9$ $\left(\mathrm{COCH}_{2}\right), 18.3\left(\mathrm{CH}_{2} \mathrm{CH}_{3}\right), 18.2\left(\mathrm{CH}_{2} \mathrm{CH}_{3}\right), 18.1\left(\mathrm{CH}_{2} \mathrm{CH}_{3}\right)$, $13.6\left(\mathrm{CH}_{2} \mathrm{CH}_{3}\right), 13.6\left(\mathrm{CH}_{2} \mathrm{CH}_{3}\right), 13.5\left(\mathrm{CH}_{2} \mathrm{CH}_{3}\right) ; \mathrm{ESIMS}: \mathrm{m} / z$ $1461[\mathrm{M}+\mathrm{H}]^{+}$, HRESIMS was calculated for $\mathrm{C}_{73} \mathrm{H}_{84} \mathrm{~N}_{6} \mathrm{NaO}_{26}$ $[\mathrm{M}+\mathrm{Na}]^{+} 1483.5333$ was found to be 1483.5317 .

\section{I,6-Di-O-[I-(4-deoxypodophyllotoxin- $4 \beta$-yl)-I,2,3-triazol-4-yl-methyl]- $\beta$-D- glucopyranose (33)}

$\mathrm{Rf}=0.60\left(\mathrm{CHCl}_{3}: \mathrm{CH}_{3} \mathrm{OH}=10: 1\right)$. White amorphous powder, yield $72 \% ; \mathrm{mp} 200^{\circ} \mathrm{C}-202^{\circ} \mathrm{C}\left(\mathrm{CHCl}_{3}-\mathrm{CH}_{3} \mathrm{OH}\right) ;[\alpha]_{\mathrm{D}}{ }^{22.9}:-52.7$ (c $\left.0.18, \mathrm{CHCl}_{3}\right) ;{ }^{1} \mathrm{H}-\mathrm{NMR}\left(\mathrm{CDCl}_{3}, 600 \mathrm{MHz}\right) \delta 7.50(\mathrm{~s}, 1 \mathrm{H})$, 7.40 (s, 1 H), 6.60 (s, 2 H), 6.59-6.57 (m, 2 H), 6.33 (s, 4 H), 6.06-5.96 (m, 6 H), 4.89 (d, $1 \mathrm{H}, J=8.0 \mathrm{~Hz}), 4.74-4.70$ (m, 4 H), 4.64-4.56 (m, 2 H), 4.44-4.42 (m, 2 H), 4.16-4.12 (m, $2 \mathrm{H}), 3.81(\mathrm{~s}, 6 \mathrm{H}), 3.77(\mathrm{~s}, 12 \mathrm{H}), 3.73-3.71(\mathrm{~m}, 2 \mathrm{H})$, 3.49-3.36 (m, $4 \mathrm{H}), 3.20-3.18$ (m, $4 \mathrm{H})$; ${ }^{13} \mathrm{C}-\mathrm{NMR}\left(\mathrm{CDCl}_{3}\right.$, $150 \mathrm{MHz}) \delta 173.5,173.5,152.8,149.2,147.9,144.7,144.3$, $137.5,134.4,133.2,124.8,123.5,110.4,108.8,108.2,102.4$, $101.9,76.4,75.2,73.3,69.8,69.6,67.4,64.4,62.5,60.7,58.6$, 56.3, 43.6, 41.5, 37.0; ESIMS: $m / z 1135[\mathrm{M}+\mathrm{H}]^{+}$, HRESIMS was calculated for $\mathrm{C}_{56} \mathrm{H}_{58} \mathrm{~N}_{6} \mathrm{NaO}_{20}[\mathrm{M}+\mathrm{Na}]^{+} 1157.3604$ was found to be 1157.3592 . 
I,6-Di-O-[I-(4-deoxypodophyllotoxin-4ßyl)-I,2,3-triazol-4-yl-methyl]-2,3,4-tri-Obenzyl- $\beta$-D-glucopyranose (34)

$\mathrm{Rf}=0.50\left(\mathrm{CHCl}_{3}: \mathrm{CH}_{3} \mathrm{OH}=30: 1\right)$. White amorphous powder, yield $86 \%$; $\mathrm{mp} 150^{\circ} \mathrm{C}-153^{\circ} \mathrm{C}\left(\mathrm{CHCl}_{3}\right) ;[\alpha]_{\mathrm{D}}^{23.4}:-48.2$ (c 0.14 , $\left.\mathrm{CHCl}_{3}\right) ;{ }^{1} \mathrm{H}-\mathrm{NMR}\left(\mathrm{CDCl}_{3}, 400 \mathrm{MHz}\right) \delta 7.32-7.24(\mathrm{~m}, 17 \mathrm{H})$, 6.60 (s, 2 H), 6.57-6.55 (m, 2 H), 6.31 (s, 4 H), 6.07-5.88 (m, 6 H), 4.85-4.79 (m, 7 H), 4.73-4.62 (m, $6 \mathrm{H}), 4.57-4.48$ (m, $2 \mathrm{H}), 4.38-4.34(\mathrm{~m}, 1 \mathrm{H}), 4.29-4.26(\mathrm{~m}, 1 \mathrm{H}), 3.81(\mathrm{~s}$, $6 \mathrm{H}), 3.76(\mathrm{~s}, 12 \mathrm{H}), 3.67-3.61(\mathrm{~m}, 2 \mathrm{H}), 3.51-3.43(\mathrm{~m}, 3 \mathrm{H})$, 3.23-3.12 (m, $4 \mathrm{H}) ;{ }^{13} \mathrm{C}-\mathrm{NMR}\left(\mathrm{CDCl}_{3}, 100 \mathrm{MHz}\right) \delta 173.2$, 153.6, 152.8, 149.3, 149.2, 148.0, 148.0, 138.4, 138.3, 137.9, $137.5,134.2,133.1,128.5,128.4,128.4,127.9,127.9,127.9$, $127.7,124.7,124.7,110.5,108.8,108.2,103.0,101.9,84.5$, 82.0, 75.7, 75.7, 74.9, 69.6, 67.3, 64.9, 60.8, 58.6, 56.3, 43.5, 41.5, 37.1; ESIMS: $m / z 1405$ [M+H] ${ }^{+}$, HRESIMS was calculated for $\mathrm{C}_{77} \mathrm{H}_{76} \mathrm{~N}_{6} \mathrm{NaO}_{20}[\mathrm{M}+\mathrm{Na}]^{+} 1427.5012$ and was found to be 1427.4997 .

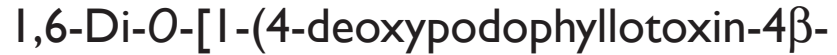
yl)-I,2,3-triazol-4-yl-methyl]-2,3,4-tri-Oacetyl- $\beta$-D-glucopyranose (35)

$\mathrm{Rf}=0.30\left(\mathrm{CHCl}_{3}: \mathrm{CH}_{3} \mathrm{OH}=15: 1\right)$. White amorphous powder, yield $80 \%$; $\mathrm{mp} 140^{\circ} \mathrm{C}-141^{\circ} \mathrm{C}\left(\mathrm{CH}_{2} \mathrm{Cl}_{2}\right) ;[\alpha]_{\mathrm{D}}^{23.1}$ : -7.2 (c 0.12 , $\left.\mathrm{CHCl}_{3}\right) ;{ }^{1} \mathrm{H}-\mathrm{NMR}\left(\mathrm{CDCl}_{3}, 600 \mathrm{MHz}\right) \delta 7.51(\mathrm{~s}, 1 \mathrm{H}), 7.41(\mathrm{~s}$, $1 \mathrm{H}), 6.72-6.71(\mathrm{~m}, 2 \mathrm{H}), 6.39-6.38(\mathrm{~m}, 4 \mathrm{H}), 6.25-6.24(\mathrm{~m}$, $2 \mathrm{H}), 6.01-5.98(\mathrm{~m}, 4 \mathrm{H}), 5.87(\mathrm{~d}, 1 \mathrm{H}, J=4.8 \mathrm{~Hz}), 5.85(\mathrm{~d}, 1 \mathrm{H}$, $J=4.8 \mathrm{~Hz}$ ), 5.20 (t, $1 \mathrm{H}, J=9.6 \mathrm{~Hz}), 5.11(\mathrm{t}, 1 \mathrm{H}, J=9.6 \mathrm{~Hz})$, 4.99-4.96 (m, $1 \mathrm{H}), 4.91$ (d, $1 \mathrm{H}, J=8.0 \mathrm{~Hz}), 4.80-4.78$ (m, 1 H), 4.71-4.69 (m, 1 H), 4.65-4.61 (m, 5 H), 4.56-4.49 (m, 2 H), 4.41-4.38 (m, $2 \mathrm{H}), 3.85$ (s, $6 \mathrm{H}), 3.82$ (s, $12 \mathrm{H}), 3.67-3.59$ (m, $2 \mathrm{H}), 3.55-3.50(\mathrm{~m}, 2 \mathrm{H}), 2.01-1.96\left(\mathrm{~m}, 9 \mathrm{H}, 3 \times \mathrm{COCH}_{3}\right)$; ${ }^{13} \mathrm{C}-\mathrm{NMR}\left(\mathrm{CDCl}_{3}, 150 \mathrm{MHz}\right) \delta 177.6,177.4,170.2,169.5$, 169.4, 153.7, 148.5, 147.8, 145.0, 144.3, 138.1, 137.2, 130.3, $125.9,123.9,110.2,106.6,104.7,101.6,99.5,73.1,72.9$, 71.2, 69.1, 68.0, 65.0, 62.4, 60.9, 59.2, 56.3, 45.3, 44.7, 38.3, $20.7\left(\mathrm{COCH}_{3}\right), 20.6\left(\mathrm{COCH}_{3}\right), 20.6\left(\mathrm{COCH}_{3}\right)$; ESIMS: $\mathrm{m} / z$ $1261[\mathrm{M}+\mathrm{H}]^{+}$, HRESIMS was calculated for $\mathrm{C}_{62} \mathrm{H}_{64} \mathrm{~N}_{6} \mathrm{NaO}_{23}$ $[\mathrm{M}+\mathrm{Na}]^{+} 1283.3921$ and was found to be 1283.3918 .

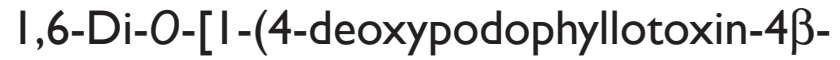
yl)- I,2,3-triazol-4-yl-methyl]-2,3,4-tri-Obutyryl- $\beta$-D-glucopyranose (36)

$\mathrm{Rf}=0.40$ (petroleum ether: ethyl acetate $=10: 1$ ). White amorphous powder, yield $75 \%$; $\mathrm{mp} 151^{\circ} \mathrm{C}-153^{\circ} \mathrm{C}\left(\mathrm{CHCl}_{3}\right)$; $[\alpha]_{\mathrm{D}}{ }^{22.8}:-55.3\left(\mathrm{c} 0.17, \mathrm{CHCl}_{3}\right) ;{ }^{1} \mathrm{H}-\mathrm{NMR}\left(\mathrm{CDCl}_{3}, 600 \mathrm{MHz}\right)$ $\delta 7.38(\mathrm{~s}, 1 \mathrm{H}), 7.30$ (s, $1 \mathrm{H}), 6.65-6.62(\mathrm{~m}, 4 \mathrm{H}), 6.35-6.34$ (m, $4 \mathrm{H}), 6.00$ (d, $2 \mathrm{H}, J=4.2 \mathrm{~Hz}), 6.03-6.01$ (m, $4 \mathrm{H}), 5.24$ (t, $1 \mathrm{H}, J=9.6 \mathrm{~Hz}), 5.13-5.08(\mathrm{~m}, 1 \mathrm{H}), 5.04-5.00(\mathrm{~m}, 1 \mathrm{H})$, 4.97-4.87 (m, 2 H), 4.81-4.76 (m, 2 H), 4.72-4.65 (m, 4 H), 4.59-4.57 (m, 2 H), 4.39-4.36 (m, $2 \mathrm{H}), 3.84$ (s, $6 \mathrm{H}), 3.79$ (s, $12 \mathrm{H}), 3.74-3.69(\mathrm{~m}, 1 \mathrm{H}), 3.61-3.58(\mathrm{~m}, 1 \mathrm{H}), 3.25-3.21$ (m, $1 \mathrm{H}), 3.14-3.11(\mathrm{~m}, 1 \mathrm{H}), 2.23-2.18\left(\mathrm{~m}, 6 \mathrm{H}, 3 \times \mathrm{COCH}_{2}\right)$, 1.59-1.54 (m, $\left.6 \mathrm{H}, 3 \times \mathrm{CH}_{2} \mathrm{CH}_{3}\right), 0.92-0.88(\mathrm{~m}, 9 \mathrm{H}, 3 \times$ $\left.\mathrm{CH}_{2} \mathrm{CH}_{3}\right) ;{ }^{13} \mathrm{C}-\mathrm{NMR}\left(\mathrm{CDCl}_{3}, 150 \mathrm{MHz}\right) \delta 173.2,173.1$, 172.6, 172.1, 172.0, 152.8, 149.4, 148.1, 137.8, 134.3, 133.2, $124.7,123.2,110.5,108.8,108.2,102.0,100.3,73.4,72.3$, 71.0, 69.3, 68.3, 67.3, 65.3, 63.0, 60.8, 58.6, 56.3, 43.6, 41.5, 37.1, $35.9\left(\mathrm{COCH}_{2}\right), 35.9\left(\mathrm{COCH}_{2}\right), 35.8\left(\mathrm{COCH}_{2}\right), 18.3$ $\left(\mathrm{CH}_{2} \mathrm{CH}_{3}\right), 18.2\left(\mathrm{CH}_{2} \mathrm{CH}_{3}\right), 18.2\left(\mathrm{CH}_{2} \mathrm{CH}_{3}\right), 13.6\left(\mathrm{CH}_{2} \mathrm{CH}_{3}\right)$, $13.5\left(\mathrm{CH}_{2} \mathrm{CH}_{3}\right), 13.4\left(\mathrm{CH}_{2} \mathrm{CH}_{3}\right)$; ESIMS: $\mathrm{m} / z 1345[\mathrm{M}+\mathrm{H}]^{+}$, HRESIMS was calculated for $\mathrm{C}_{68} \mathrm{H}_{76} \mathrm{~N}_{6} \mathrm{NaO}_{23}[\mathrm{M}+\mathrm{Na}]^{+}$ 1367.4860 and was found to be 1367.4844 .

\section{I,6-Di-O-[I-(4-deoxy-4'-}

demethylpodophyllotoxin-4 $\beta$-yl)- I,2,3-tri azol-4-yl-methyl]- $\beta$-D-glucopyranose (37) $\mathrm{Rf}=0.20\left(\mathrm{CHCl}_{3}: \mathrm{CH}_{3} \mathrm{OH}=9: 1\right)$. White amorphous powder, yield $76 \%$; mp $195^{\circ} \mathrm{C}-196^{\circ} \mathrm{C}\left(\mathrm{CHCl}_{3}-\mathrm{CH}_{3} \mathrm{OH}\right)$; $[\alpha]_{\mathrm{D}}{ }^{23.5}:-124.6$ (c 0.14 , Pyridine); ${ }^{1} \mathrm{H}-\mathrm{NMR}\left(\mathrm{C}_{5} \mathrm{D}_{5} \mathrm{~N}\right.$, $600 \mathrm{MHz}) \delta 8.20(\mathrm{~s}, 1 \mathrm{H}), 8.17(\mathrm{~s}, 1 \mathrm{H}), 6.85(\mathrm{~m}, 4 \mathrm{H}), 6.80$ $6.79(\mathrm{~m}, 4 \mathrm{H}), 6.55(\mathrm{~d}, 1 \mathrm{H}, J=4.8 \mathrm{~Hz}), 6.50(\mathrm{~d}, 1 \mathrm{H}, J=4.8 \mathrm{~Hz})$, $5.95(\mathrm{~s}, 4 \mathrm{H}), 5.93(\mathrm{~d}, 1 \mathrm{H}, J=7.8 \mathrm{~Hz}), 5.33-5.31(\mathrm{~m}, 1 \mathrm{H})$, 5.14-5.12 (m, 1 H), 4.99-4.94 (m, $5 \mathrm{H}), 4.41-4.37(\mathrm{~m}$, $1 \mathrm{H}), 4.15-4.10(\mathrm{~m}, 1 \mathrm{H}), 4.00-3.95(\mathrm{~m}, 1 \mathrm{H}), 3.83-3.76(\mathrm{~m}$, $3 \mathrm{H}), 3.73(\mathrm{~s}, 12 \mathrm{H}), 3.67-3.61(\mathrm{~m}, 3 \mathrm{H}), 3.44-3.36(\mathrm{~m}, 4 \mathrm{H})$; ${ }^{13} \mathrm{C}-\mathrm{NMR}\left(\mathrm{C}_{5} \mathrm{D}_{5} \mathrm{~N}, 150 \mathrm{MHz}\right) \delta 174.0,173.9,149.0,148.6$, 148.0, 145.6, 145.4, 137.3, 134.3, 129.9, 126.3, 124.5, 110.6, 109.6, 109.1, 104.3, 102.2, 78.3, 77.0, 74.7, 71.4, 71.2, 67.8, 65.3, 63.2, 58.6, 56.4, 44.0, 41.9, 37.8; ESIMS: $\mathrm{m} / \mathrm{z}$ $1107[\mathrm{M}+\mathrm{H}]^{+}$, HRESIMS was calculated for $\mathrm{C}_{54} \mathrm{H}_{54} \mathrm{~N}_{6} \mathrm{NaO}_{20}$ $[\mathrm{M}+\mathrm{Na}]^{+} 1129.3291$ and was found to be 1129.3281 .

\section{I,6-Di-O-[I-(4-deoxy-4'-}

demethylpodophyllotoxin-4 $\beta$-yl)- I,2,3triazol-4-yl-methyl]-2,3,4-tri-O-benzyl- $\beta$ D-glucopyranose (38)

$\mathrm{Rf}=0.20\left(\mathrm{CHCl}_{3}: \mathrm{CH}_{3} \mathrm{OH}=30: 1\right)$. White amorphous powder, yield $85 \%$; mp $174^{\circ} \mathrm{C}-176^{\circ} \mathrm{C}\left(\mathrm{CHCl}_{3}\right) ;[\alpha]_{\mathrm{D}}^{23.5}:-58.8$ (c $\left.0.20, \mathrm{CHCl}_{3}\right) ;{ }^{1} \mathrm{H}-\mathrm{NMR}\left(\mathrm{CDCl}_{3}, 400 \mathrm{MHz}\right) \delta 7.32-7.24$ (m, $17 \mathrm{H}), 6.59$ (s, $2 \mathrm{H}), 6.56-6.54$ (m, $2 \mathrm{H}), 6.32$ (s, $4 \mathrm{H})$, $6.06(\mathrm{~d}, 1 \mathrm{H}, J=4.0 \mathrm{~Hz}), 6.01(\mathrm{~d}, 1 \mathrm{H}, J=4.0 \mathrm{~Hz}), 5.97-5.87$ (m, $4 \mathrm{H}), 4.91-4.79$ (m, $7 \mathrm{H}), 4.72-4.67$ (m, $4 \mathrm{H}), 4.63$ (d, 2 $\mathrm{H}, J=4.0 \mathrm{~Hz}), 4.57-4.55(\mathrm{~m}, 1 \mathrm{H}), 4.50-4.48(\mathrm{~m}, 1 \mathrm{H}), 4.34$ $4.31(\mathrm{~m}, 1 \mathrm{H}), 4.26-4.24(\mathrm{~m}, 1 \mathrm{H}), 4.14-4.09(\mathrm{~m}, 1 \mathrm{H}), 3.78$ (s, 12 H), 3.69-3.61 (m, 2 H), 3.51-3.40 (m, 3 H), 3.22-3.11 
$(\mathrm{m}, 4 \mathrm{H}) ;{ }^{13} \mathrm{C}-\mathrm{NMR}\left(\mathrm{CDCl}_{3}, 100 \mathrm{MHz}\right) \delta 173.3,149.3,148.0$, $147.9,146.6,144.8,138.5,138.3,137.9,134.4,129.8,128.5$, $128.4,128.4,127.9,127.9,127.9,127.7,124.8,123.0,110.5$, $110.4,107.8,103.0,101.8,84.5,81.9,75.7,74.9,74.7,69.6$, 67.4, 65.0, 63.2, 58.5, 56.5, 43.4, 41.6, 37.0; ESIMS: $\mathrm{m} / z$ $1377[\mathrm{M}+\mathrm{H}]^{+}$, HRESIMS was calculated for $\mathrm{C}_{75} \mathrm{H}_{72} \mathrm{~N}_{6} \mathrm{NaO}_{20}$ $[\mathrm{M}+\mathrm{Na}]^{+} 1399.4699$ was found to be 1399.4683 .

\section{I,6-Di-O-[I-(4-deoxy-4'- demethylpodophyllotoxin-4 $3-y \mid)-I, 2,3-$ triazol-4-yl-methyl]-2,3,4-tri-O-acetyl- $\beta$ - D-glucopyranose (39)}

$\mathrm{Rf}=0.50\left(\mathrm{CHCl}_{3}: \mathrm{CH}_{3} \mathrm{OH}=15: 1\right)$. White amorphous powder, yield $84 \%$; mp $183^{\circ} \mathrm{C}-184^{\circ} \mathrm{C}\left(\mathrm{CHCl}_{3}\right) ;[\alpha]_{\mathrm{D}}^{23.3}:-55.9$ (c 0.18 , $\left.\mathrm{CHCl}_{3}\right) ;{ }^{1} \mathrm{H}-\mathrm{NMR}\left(\mathrm{CDCl}_{3}, 400 \mathrm{MHz}\right) \delta 7.33(\mathrm{~s}, 1 \mathrm{H}), 7.27$ (s, 1 H), 6.62-6.59 (m, 4 H), 6.32-6.31 (m, 4 H), 6.09-6.07 (m, $2 \mathrm{H}), 6.01-5.98(\mathrm{~m}, 4 \mathrm{H}), 5.16(\mathrm{t}, 1 \mathrm{H}, J=9.6 \mathrm{~Hz}), 5.04(\mathrm{t}$, $1 \mathrm{H}, J=9.6 \mathrm{~Hz}), 4.96-4.92(\mathrm{~m}, 1 \mathrm{H}), 4.80$ (d, $1 \mathrm{H}, J=8.0 \mathrm{~Hz})$, 4.76-4.72 (m, $2 \mathrm{H}), 4.64-4.54(\mathrm{~m}, 7 \mathrm{H}), 4.36-4.32$ (m, $2 \mathrm{H})$, $3.78(\mathrm{~s}, 12 \mathrm{H}), 3.70-3.67(\mathrm{~m}, 1 \mathrm{H}), 3.60-3.56(\mathrm{~m}, 1 \mathrm{H})$, $3.26-3.19(\mathrm{~m}, 2 \mathrm{H}), 1.98-1.93\left(\mathrm{~m}, 9 \mathrm{H}, 3 \times \mathrm{COCH}_{3}\right) ;{ }^{13} \mathrm{C}-$ NMR $\left(\mathrm{CDCl}_{3}, 100 \mathrm{MHz}\right) \delta 173.3,173.1,170.2,169.4,169.4$, 149.3, 148.0, 146.6, 144.8, 144.4, 134.3, 133.4, 129.8, 124.6, $123.3,110.5,108.8,107.8,101.9,100.0,73.1,72.7,71.2$, 69.1, 68.6, 67.3, 65.0, 62.8, 58.6, 56.5, 43.4, 42.1, 41.6, 37.0, $20.6\left(\mathrm{COCH}_{3}\right), 20.6\left(\mathrm{COCH}_{3}\right), 20.5\left(\mathrm{COCH}_{3}\right)$; ESIMS: $\mathrm{m} / z$ $1317[\mathrm{M}+\mathrm{H}]^{+}$, HRESIMS was calculated for $\mathrm{C}_{66} \mathrm{H}_{72} \mathrm{~N}_{6} \mathrm{NaO}_{23}$ $[\mathrm{M}+\mathrm{Na}]^{+} 1339.4547$ and was found to be 1339.4526 .

\section{I,6-Di-O-[I-(4-deoxy-4'-

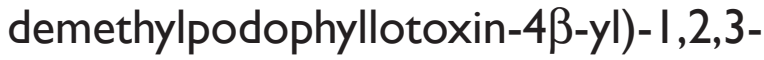 triazol-4-yl-methyl]-2,3,4-tri-O-butyryl- $\beta$-D-glucopyranose (40)}

$\mathrm{Rf}=0.20$ (petroleum ether: ethyl acetate $=10: 1$ ). White amorphous powder, yield $82 \%$; mp $184^{\circ} \mathrm{C}-186^{\circ} \mathrm{C}\left(\mathrm{CHCl}_{3}\right)$; $[\alpha]_{\mathrm{D}}{ }^{23.4}:-56.4\left(\mathrm{c} 0.28, \mathrm{CHCl}_{3}\right) ;{ }^{1} \mathrm{H}-\mathrm{NMR}\left(\mathrm{CDCl}_{3}, 400 \mathrm{MHz}\right)$ $\delta 7.35$ (s, 1 hour), $7.28(\mathrm{~s}, 1 \mathrm{H}), 6.60(\mathrm{~s}, 2 \mathrm{H}), 6.59-6.58$ (m, 2 H), 6.32-6.31 (m, 4 H), 6.06-5.97 (m, 6 H), 5.21 (t, $1 \mathrm{H}, J=9.6 \mathrm{~Hz}), 5.05(\mathrm{t}, 1 \mathrm{H}, J=9.6 \mathrm{~Hz}), 5.00-4.95(\mathrm{~m}, 1 \mathrm{H})$, 4.82-4.78 (m, $2 \mathrm{H}), 4.74-4.71(\mathrm{~m}, 2 \mathrm{H}), 4.65-4.62(\mathrm{~m}, 4 \mathrm{H})$, 4.56-4.52 (m, $2 \mathrm{H}), 4.33-4.30(\mathrm{~m}, 2 \mathrm{H}), 3.77(\mathrm{~s}, 12 \mathrm{H})$, $3.71-3.65(\mathrm{~m}, 1 \mathrm{H}), 3.59-3.53(\mathrm{~m}, 1 \mathrm{H}), 3.20-3.16(\mathrm{~m}$, $1 \mathrm{H}), 3.09-3.04$ (m, $1 \mathrm{H}), 2.20-2.13\left(\mathrm{~m}, 6 \mathrm{H}, 3 \times \mathrm{COCH}_{2}\right)$, 1.56-1.50 (m, 6 H, 3× $\left.\mathrm{CH}_{2} \mathrm{CH}_{3}\right), 0.89-0.81(\mathrm{~m}, 9 \mathrm{H}, 3 \times$ $\left.\mathrm{CH}_{2} \mathrm{CH}_{3}\right) ;{ }^{13} \mathrm{C}-\mathrm{NMR}\left(\mathrm{CDCl}_{3}, 100 \mathrm{MHz}\right) \delta 173.3,173.2$, 172.6, 172.0, 171.9, 149.3, 149.3, 147.9, 144.9, 144.5, 134.3, $133.3,129.7,124.6,123.3,100.4,108.7,107.8,101.9,100.2$, $73.3,72.3,70.9,68.3,67.3,65.2,62.9,58.6,56.5,43.4,41.5$,
37.0, $35.9\left(\mathrm{COCH}_{2}\right), 35.8\left(\mathrm{COCH}_{2}\right), 35.8\left(\mathrm{COCH}_{2}\right), 18.3$ $\left(\mathrm{CH}_{2} \mathrm{CH}_{3}\right), 18.2\left(\mathrm{CH}_{2} \mathrm{CH}_{3}\right), 18.2\left(\mathrm{CH}_{2} \mathrm{CH}_{3}\right), 13.6\left(\mathrm{CH}_{2} \mathrm{CH}_{3}\right)$, $13.5\left(\mathrm{CH}_{2} \mathrm{CH}_{3}\right), 13.4\left(\mathrm{CH}_{2} \mathrm{CH}_{3}\right)$; ESIMS: $m / z 1233[\mathrm{M}+\mathrm{H}]^{+}$, HRESIMS was calculated for $\mathrm{C}_{60} \mathrm{H}_{50} \mathrm{~N}_{6} \mathrm{NaO}_{23}[\mathrm{M}+\mathrm{Na}]^{+}$ 1255.3608 and was found to be 1255.3595 .

\section{Cell culture and cytotoxicity assay}

The following human tumor cell lines were used: HL-60, SMMC-7721, A-549, MCF-7, and SW480. All the cells were cultured in RMPI-1640 or DMEM medium (Hyclone, Logan, UT, USA), supplemented with $10 \%$ fetal bovine serum (Hyclone) at $37^{\circ} \mathrm{C}$ in a humidified atmosphere with $5 \% \mathrm{CO}_{2}$. Cell viability was assessed by conducting colorimetric measurements of the amount of insoluble formazan formed in living cells based on the reduction of 3-(4,5dimethyl-thiazol-2-yl)-2,5-diphenyltetrazolium bromide (MTT) (Sigma-Aldrich Co., St Louis, MO, USA). Briefly, adherent cells $(100 \mu \mathrm{L})$ were seeded into each well of a 96-well cell culture plate and allowed to adhere for 12 hours before drug addition, while suspended cells were seeded just before drug addition, both with an initial density of $1 \times 10^{5}$ cells $/ \mathrm{mL}$ in $100 \mu \mathrm{L}$ of medium. Each tumor cell line was exposed to the test compound at various concentrations in triplicate for 48 hours. After the incubation, MTT (100 $\mu \mathrm{g}$ ) was added to each well, and the incubation continued for 4 hours at $37^{\circ} \mathrm{C}$. The cells lysed with SDS $(200 \mu \mathrm{L})$ after removal of $100 \mu \mathrm{L}$ of medium. The OD of lysate was measured at $595 \mathrm{~nm}$ in a 96 -well microtiter plate reader (Bio-Rad 680).

\section{Acknowledgments}

This work was financially supported by Yunnan province (grant nos 2015HB093 and 2015FB168) and the National Key Research and Development Program of China (grant no 2017YFD0201402). The authors thank the staff of analytical group of the State Key Laboratory of Phytochemistry and Plant Resources in West China, Kunming Institute of Botany, Chinese Academy of Sciences, for measurements of all spectra.

\section{Disclosure}

The authors report no conflicts of interest in this work.

\section{References}

1. Castro MA, del Corral JM, García PA, et al. Synthesis and biological evaluation of new podophyllic aldehyde derivatives with cytotoxic and apoptosis-inducing activities. J Med Chem. 2010;53(3):983-993.

2. Sk UH, Dixit D, Sen E. Comparative study of microtubule inhibitors estramustine and natural podophyllotoxin conjugated PAMAM dendrimer on glioma cell proliferation. Eur J Med Chem. 2013;68:47-57. 
3. Ma Y, Fang S, Li H, et al. Biological evaluation and molecular modelling study of podophyllotoxin derivatives as potent inhibitors of tubulin polymerization. Chem Biol Drug Des. 2013;82(1):12-21.

4. Jordan A, Hadfield JA, Lawrence NJ, McGown AT. Tubulin as a target for anticancer drugs: agents which interact with the mitotic spindle. Med Res Rev. 1998;18(4):259-296.

5. Wang ZQ, Kuo YH, Schnur D, et al. Antitumor agents. 113. New 4 beta-arylamino derivatives of 4'-O-demethylepipodophyllotoxin and related compounds as potent inhibitors of human DNA topoisomerase II. J Med Chem. 1990;33(9):2660-2666.

6. Hande KR. Etoposide: four decades of development of a topoisomerase II inhibitor. Eur J Cancer. 1998;34(10):1514-1521.

7. Brewer CF, Loike JD, Horwitz SB, Sternlicht H, Gensler WJ. Conformational analysis of podophyllotoxin and its congeners. Structure activity relationship in microtubule assembly. J Med Chem. 1979; 22(3):215-221.

8. Niu L, Wang Y, Wang C, et al. Structure of 4'-demethylepipodophyllotoxin in complex with tubulin provides a rationale for drug design. Biochem Biophys Res Commun. 2017;493(1):718-722.

9. Sackett DL. Podophyllotoxin, steganacin and combretastatin: natural products that bind at the colchicine site of tubulin. Pharmacol Ther. 1993;59(2):163-228.

10. Moraes RM, Dayan FE, Canel C. The lignans of Podophyllum. Stud Nat Prod Chem. 2002;26:149-182.

11. Yu X, Che Z, Xu H. Recent Advances in the Chemistry and Biology of Podophyllotoxins. Chem Eur J. 2017;23(19):4467-4526.

12. Kamal A, Hussaini SM, Malik MS. Recent developments towards podophyllotoxin congeners as potential apoptosis inducers. Anticancer Agents Med Chem. 2015;15(5):565-574.

13. Bhat BA, Reddy PB, Agrawal SK, Saxena AK, Kumar HM, Qazi GN. Studies on novel 4beta-[(4-substituted)-1,2,3-triazol-1-yl] podophyllotoxins as potential anticancer agents. Eur J Med Chem. 2008;43(10): 2067-2072.

14. Reddy DM, Srinivas J, Chashoo G, Saxena AK, Sampath Kumar HM. $4 \beta$-[(4-Alkyl)-1,2,3-triazol-1-yl] podophyllotoxins as anticancer compounds: design, synthesis and biological evaluation. Eur J Med Chem. 2011;46(6):1983-1991.

15. Chen H, Zuo S, Wang X, et al. Synthesis of $4 \beta$-triazole-podophyllotoxin derivatives by azide-alkyne cycloaddition and biological evaluation as potential antitumor agents. Eur J Med Chem. 2011;46(9):4709-4714.

16. $\mathrm{Zi} \mathrm{CT}, \mathrm{Xu}$ FQ, Li GT, et al. Synthesis and anticancer activity of glucosylated podophyllotoxin derivatives linked via $4 \beta$-triazole rings. Molecules. 2013;18(11):13992-14012.

17. Zi CT, Liu ZH, Li GT, et al. Design, synthesis, and cytotoxicity of perbutyrylated glycosides of $4 \beta$-triazolopodophyllotoxin derivatives. Molecules. 2015;20(2):3255-3280.

18. Zi CT, Yang L, Gao W, et al. Click glycosylation for the synthesis of 1, 2, 3-triazole-linked picropodophyllotoxin glycoconjugates and their anticancer activity. Chemistry Select. 2017;2(18):5038-5044.
19. Kamal A, Laxman E, Khanna GB, et al. Design, synthesis, biological evaluation and QSAR studies of novel bisepipodophyllotoxins as cytotoxic agents. Bioorg Med Chem. 2004;12(15):4197-4209.

20. Passarella D, Peretto B, Blasco y Yepes R, et al. Synthesis and biological evaluation of novel thiocolchicine-podophyllotoxin conjugates. Eur J Med Chem. 2010;45(1):219-226.

21. Bock VD, Hiemstra H, van Maarseveen JH. CuI-Catalyzed AlkyneAzide "Click" Cycloadditions from a Mechanistic and Synthetic Perspective. Eur J Org Chem. 2006;2006(1):51-68.

22. Kolb HC, Finn MG, Sharpless KB. Click chemistry: diverse chemical function from a few good reactions. Angew Chem Int Ed Engl. 2001; 40(11):2004-2021.

23. Nielsen MM, Dimitrov I, Takamuku S, Jannasch P, Jankova K, Hvilsted S. Dendronized polymer architectures for fuel cell membranes. Fuel Cells. 2013;13(3):342-354.

24. Nazaré M, Waldmann H. Synthesis of the (9S, 18R) diastereomer of cyclamenol A. Angew Chem Int Ed Engl. 2000;39(6):1125-1128.

25. Smith AB, Ott GR. Total Synthesis of (-)-Macrolactin A. J Am Chem Soc. 1996;118(51):13095-13096.

26. Matsuo I, Isomura M, Miyazaki T, Sakakibara T, Ajisaka K. Chemoenzymatic synthesis of the branched oligosaccharides which correspond to the core structures of N-linked sugar chains. Carbohydr Res. 1997; 305(3-4):401-413.

27. Sureshkumar G, Hotha S. Gold mediated glycosylations: selective activation of propargyl 1,2-orthoesters in the presence of aglycones containing a propargyl moiety. Chem Commun (Camb). 2008;(36): 4282-4284.

28. Hansen HF, Jensen RB, Willumsen AM, et al. New compounds related to podophyllotoxin and congeners: synthesis, structure elucidation and biological testing. Acta Chem Scand. 1993;47(12):1190-1200.

29. Zi CT, Yang D, Dong FW, et al. Synthesis and antitumor activity of novel per-butyrylated glycosides of podophyllotoxin and its derivatives. Bioorg Med Chem. 2015;23(7):1437-1446.

30. de Oliveira PF, Alves JM, Damasceno JL, Oliveira RAM, Dias HJ, Crotti AEM. Cytotoxicity screening of essential oils in cancer cell lines. Rev Bras Farmacogn. 2012;22:88-93.

31. Shi JF, Wu P, Jiang ZH, Wei XY. Synthesis and tumor cell growth inhibitory activity of biotinylated annonaceous acetogenins. Eur J Med Chem. 2014;71:219-228.

32. Suffness M, Pezzuto JM. Assays related to cancer drug discovery. In: Hostettmann K, editor. Methods in Plant Biochemistry: Assays for Bioactivity. London: Academic Press; 1990:71-133.

33. Bézivin C, Tomasi S, Lohézic-Le Dévéhat F, Boustie J. Cytotoxic activity of some lichen extracts on murine and human cancer cell lines. Phytomedicine. 2003;10(6-7):499-503
Drug Design, Development and Therapy

\section{Publish your work in this journal}

Drug Design, Development and Therapy is an international, peerreviewed open-access journal that spans the spectrum of drug design and development through to clinical applications. Clinical outcomes, patient safety, and programs for the development and effective, safe, and sustained use of medicines are the features of the journal, which
Dovepress

has also been accepted for indexing on PubMed Central. The manuscript management system is completely online and includes a very quick and fair peer-review system, which is all easy to use. Visit http://www.dovepress.com/testimonials.php to read real quotes from published authors. 